\title{
A Case Study of Offshore Advection of Boundary Layer Rolls over a Stably Stratified Sea Surface
}

\author{
Nina Svensson, ${ }^{1}$ Erik Sahlée, ${ }^{1}$ Hans Bergström, ${ }^{1}$ Erik Nilsson, ${ }^{1}$ \\ Merete Badger, ${ }^{2}$ and Anna Rutgersson ${ }^{1}$ \\ ${ }^{1}$ Department of Earth Sciences, Uppsala University, Villavägen 16, 75236 Uppsala, Sweden \\ ${ }^{2}$ Department of Wind Energy, Technical University of Denmark, Frederiksborgvej 399, 4000 Roskilde, Denmark \\ Correspondence should be addressed to Nina Svensson; nina.svensson@geo.uu.se
}

Received 7 April 2017; Accepted 27 August 2017; Published 15 October 2017

Academic Editor: Enrico Ferrero

Copyright (C) 2017 Nina Svensson et al. This is an open access article distributed under the Creative Commons Attribution License, which permits unrestricted use, distribution, and reproduction in any medium, provided the original work is properly cited.

Streaky structures of narrow $(8-9 \mathrm{~km})$ high wind belts have been observed from SAR images above the Baltic Sea during stably stratified conditions with offshore winds from the southern parts of Sweden. Case studies using the WRF model and in situ aircraft observations indicate that the streaks originate from boundary layer rolls generated over the convective air above Swedish mainland, also supported by visual satellite images showing the typical signature cloud streets. The simulations indicate that the rolls are advected and maintained at least 30-80 km off the coast, in agreement with the streaks observed by the SAR images. During evening when the convective conditions over land diminish, the streaky structures over the sea are still seen in the horizontal wind field; however, the vertical component is close to zero. Thus advected feature from a land surface can affect the wind field considerably for long times and over large areas in coastal regions. Although boundary layer rolls are a well-studied feature, no previous study has presented results concerning their persistence during situations with advection to a strongly stratified boundary layer. Such conditions are commonly encountered during spring in coastal regions at high latitudes.

\section{Introduction}

Larger areas of coherent streaky structures are often seen in satellite images over sea surface. In many cases this is due to an instability pattern in an area with certain atmospheric conditions. We will call this phenomenon boundary layer rolls, but many other names for the same phenomenon exist in literature, like longitudinal rolls, horizontal roll vortices, and cloud streets to mention a few. Boundary layer rolls are elongated vertical circulations aligned approximately in the along-wind direction, consisting of counterrotating vortices, creating areas of alternating up- and downward motion. This vertical wind speed pattern also translates into the horizontal wind field, where lower horizontal winds are seen in the upwind regions and higher in the downwind regions, which makes it possible to observe the rolls in satellite images where wind speed is inferred from backscatter from the roughness elements at the sea surface. In this study we will investigate possible creation mechanisms of boundary layer rolls that exist in the coastal zone. Other types of streaky structures elongated in the along-wind direction have also been observed and can be formed by lee effects from terrain [1] or from orography inhomogeneities [2]. In these types of features, however, each streak is created from a certain source, behaving like a wake.

The formation of boundary layer rolls is attributed to two mechanisms, thermal instability and dynamic instability, often in combination. Thus, boundary layer rolls are often formed in convective boundary layers. The most important dynamic instability in the atmosphere is inflection point instability, which is characterized by an inflection point in the cross-roll wind profile, around which a vorticity maximum can form (see Atkinson and Zhang [3] and references therein), and in the case of dynamic instability boundary layer rolls form in neutral conditions.

Boundary layer rolls are often observed for relatively high wind speeds, at least more than $5 \mathrm{~m} \mathrm{~s}^{-1}$ [4]. According to the review by Atkinson and Zhang [3] typical wind speed values 
during roll occurrence are $15 \mathrm{~m} \mathrm{~s}^{-1}$, but there are observations ranging over a wide variety of wind speeds. Typical wavelengths are $2-5 \mathrm{~km}$, and typical depths are $0.5-2 \mathrm{~km}$, but boundary layer rolls have been observed with wavelengths in the range $1-20 \mathrm{~km}$. Roll length has been observed to vary from a few tens to $200 \mathrm{~km}$. Boundary layer rolls can increase vertical fluxes of momentum, heat, and moisture considerably [5-7] and contribute to initiation of deep convection and storm development [8].

Many observational studies on rolls have been performed; see the reviews by Atkinson and Zhang [3] and Young et al. [9] for a summary and, for example, Hartmann et al. [10], Weckwerth et al. [4], Brümmer [6], and Müller et al. [11] for later studies. Most of the observational studies concerning boundary layer rolls have been performed in cold-air outbreaks over water [3], when air flows from a cold land or ice surface out over relatively warmer water. This causes convective conditions over the sea surface, where boundary layer rolls are formed by thermal instability. An evolution is generally observed, with the boundary layer rolls increasing in wavelength and turning into convective cells at some distance from the coast or ice sheet [6]. Similarly, Weckwerth et al. [12] studied the diurnal cycle of boundary layer rolls over land and showed that boundary layer rolls were the first type of organized convection in the growing convective boundary layer. The rolls then turned into cellular or unorganized convection as the boundary layer instability increased. Rolls observed during cold-air outbreaks often occur during strong convection because of the large air-sea temperature differences. In contrast, boundary layer rolls may also occur during weaker convection, as shown by Smedman [13] from a case study in the Baltic Sea, where boundary layer rolls were observed in a layer of only a few hundred metres height.

There are only few observational studies of boundary layer rolls where water is colder than the air above, which is the focus of this study. Alpers and Brümmer [14] and Müller et al. [11] detected boundary layer rolls from SAR images over the North Sea during a positive land-sea temperature contrast of a few degrees, attributing the rolls to dynamic instability.

Boundary layer rolls have been successfully simulated by LES models [1, 5, 8, 15-17] and in a few cases also by numerical weather prediction models $[18,19]$. The advantage of using weather prediction models is the ability to simulate a longer time period, to obtain the diurnal variations, and to include the large-scale forcing and realistic topography, which gives the horizontal variations over extended areas.

This study is set in the Baltic Sea, which is a small, semienclosed sea at relatively high latitudes. Seasonal temperature variations are large, and this gives rise to land-sea temperature differences as high as $20^{\circ} \mathrm{C}$ in spring and summer [20] when there is warm-air advection from the warmer land surface out over the colder sea. This warm-air advection creates stable conditions over the sea surface, affecting the Baltic Sea across its whole extent [21]. Similar conditions are encountered during spring over large parts of the coastal regions at high latitudes.

In this study we will show observations of boundary layer rolls from satellite images and aircraft measurements over the Baltic Sea during four cases. In contrast to many of the earlier studies, there is a stable temperature gradient over the sea surface in all studied cases. Simulations with a numerical weather prediction model are used to study the characteristics of the rolls and their formation and maintenance over the stable sea surface. In Section 2 the observational data, simulation setup, and weather situation during the cases are described. In Section 3 the results from simulations and observations are presented, and one of the most clear cases is presented in more detail. Discussion and conclusions are given in Section 4.

\section{Data and Methods}

2.1. Aircraft Data. A field campaign was conducted over the Baltic Sea on 1-4 May 1997 by the UK Meteorological Office as part of the EU project STAARTE (Scientific Training and Access to Aircraft for Atmospheric Research Throughout Europe), using the Hercules meteorological research aircraft C-130. Several aircraft flight legs were flown over the sea surface, both in the horizontal and in the vertical direction. The technical details of the airplane and instrumentation are described in Anderson [22]. During two of the days, 2 and 3 May 1997, boundary layer rolls were formed, and on these days there were two coast-parallel horizontal flight legs during each day capturing the boundary layer rolls. These flight legs were taken in the approximate cross-roll direction along the coastline of the Swedish mainland and the island of Gotland at the height of $\sim 30-40 \mathrm{~m}$ and at a distance of $\sim 20 \mathrm{~km}$ from the coast. Eight slant profiles were flown in the area between Gotland and the mainland during a time of approximately 1 hour. From these, an average profile was calculated and used for determination of the Richardson gradient number, between heights of 25 and $140 \mathrm{~m}$. For this study measurements of temperature, humidity, and wind were used, where temperature was measured by a Platinum resistance sensor with an accuracy of $\pm 0.3^{\circ} \mathrm{C}$, dew point temperature was measured by a thermoelectric hygrometer with an accuracy of $\pm 0.25^{\circ} \mathrm{C}$, and wind speed was measured by a pitot-static system with an accuracy of $\pm 0.5 \mathrm{~m} \mathrm{~s}^{-1}$.

2.2. SAR Images. Boundary layer rolls can be detected by satellite imagery, where they are manifested either as cloud bands or as streaks in the horizontal wind field. In this case, satellite images were obtained from the ASAR (Advanced Synthetic Aperture Radar) instrument on board the Envisat satellite, which has up to two overpasses a day in the Baltic Sea area. The ASAR instrument measures the Bragg scattering from $\mathrm{cm}$-scale capillary and gravity waves which are generated by the local wind stress at the sea surface. The radar backscatter can be related to the equivalent neutral wind at $10 \mathrm{~m}$ height. The advantages of using the wind field for roll detection instead of visual satellite imagery is that it can be used even during cloud-free conditions. Moreover, it has been suggested that there can be several scales of roll motion, with a smaller convective scale and a larger cloud band scale $[3,23,24]$. By studying the wind field, the smaller scale would then be detected. 
The SAROPS (SAR Ocean Products System) developed by NOAA (the US National Oceanographic and Atmospheric Administration) was used for retrieval of wind speed from radar backscatter through inversion of the empirical wind retrieval algorithm CMOD5.n [25]. Pixels in the original SAR data were averaged to $500 \mathrm{~m} \times 500 \mathrm{~m}$ before the wind inversion in order to eliminate effects of random noise and longer-period waves which can modulate the radar incidence angle. This also means that boundary layer rolls with wavelengths smaller than approximately $2 \mathrm{~km}$ will be filtered out. Information about the wind direction is needed as input for the algorithm, and it was obtained from simulated wind fields from the GFS (Global Forecast System) available from NOAA. The wind direction data had a horizontal resolution of $0.5^{\circ}$ latitude and longitude and a time resolution of 3 hours. It was interpolated spatially to the pixel size of the averaged SAR data.

Comparisons of winds retrieved from SAR to tower observations in the Baltic Sea have previously shown a RMS error of $1.17 \mathrm{~m} \mathrm{~s}^{-1}$ and a bias of $-0.25 \mathrm{~m} \mathrm{~s}^{-1}$ [26]. These results were based on an earlier wind retrieval algorithm, CMOD5, which on average gives wind speeds that are $0.7 \mathrm{~m} \mathrm{~s}^{-1}$ lower than those of CMOD5.n. This is due to a bias correction of $0.5 \mathrm{~m} \mathrm{~s}^{-1}$ and an average difference of $0.2 \mathrm{~m} \mathrm{~s}^{-1}$ between real winds and equivalent neutral winds [27]. Effects of atmospheric stability are not taken into account during SAR wind retrieval and this leads to uncertainty in the absolute wind speed values; especially during highly stable or unstable conditions. Since we are primarily interested in the spatial wind variability associated with boundary layer rolls and the wind speed amplitude, the absolute accuracy of SAR wind speeds is less important in this study.

Satellite images from the year 2011 were examined in search for boundary layer rolls, and during this year there were on average 11 images per month covering a larger part of the southern Baltic Sea. During this year, two clear cases of boundary layer rolls were observed, both taking place in May. These cases will be presented in Section 2.3.

2.3. Meteorological Conditions during Cases. Four days with boundary layer rolls circulations covering a large area will be shown here. The characteristic weather situation during all cases was slightly convective conditions over land, and westerly or northwesterly winds originating over the Swedish mainland were directed out over the Baltic Sea, creating stable conditions above the sea surface due to warm-air advection.

During the period of the flight measurement campaign there were two days with roll activity, 2 and 3 May 1997. During these days, a low pressure system was moving in from the Norwegian Sea towards northern Scandinavia. The cold front associated with this low pressure passed Sweden on 2 May, bringing in colder air. Data from ground stations maintained by SMHI (Swedish Meteorological Institute) showed that the daily maximum temperature on the mainland was $15-19^{\circ} \mathrm{C}$ on 2 May and $10-14^{\circ} \mathrm{C}$ on 3 May. SST charts acquired from SMHI showed a temperature of $4-5^{\circ} \mathrm{C}$ in the parts of the Baltic Sea which will be studied here. These conditions gave rise to a land-sea temperature contrast of $10-15^{\circ} \mathrm{C}$ on 2 May and

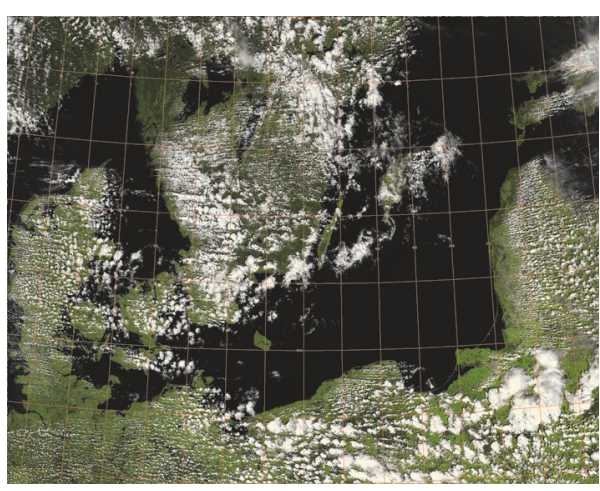

FIgUre 1: Visual satellite image from the Aqua MODIS satellite from 25 May 2011, 1205 UTC.

$5-10^{\circ} \mathrm{C}$ on 3 May. The wind direction during the time of roll activity was westerly $\left(260-300^{\circ}\right)$ on 2 May and northwesterly $\left(290-320^{\circ}\right)$ on 3 May. The wind speed at $10 \mathrm{~m}$ height was $5-10 \mathrm{~m} \mathrm{~s}^{-1}$ on both days.

During 17 and 25 May 2011 boundary layer rolls were observed from SAR images. On 17 May the wind direction was southeasterly in the morning, turning westerly after around 1500 UTC when a weak frontal system was passing. During 25 May winds were westerly during almost the whole day, circulating around a low pressure in northern Sweden. Data from SMHI surface stations showed a wind speed at $10 \mathrm{~m}$ with height of $2-12 \mathrm{~m} \mathrm{~s}^{-1}$ on 17 May and $3-9 \mathrm{~m} \mathrm{~s}^{-1}$ on 25 May. Maximum daytime temperature over land was $10-17^{\circ} \mathrm{C}$ on both days, with the warmest temperatures along the coast and in the northern parts of the domain. The temperature over the sea was $7-10^{\circ} \mathrm{C}$ with the warmest temperatures along the coast. The mean temperature over land was $13^{\circ} \mathrm{C}$, thus corresponding to a land-sea temperature gradient of $3-6^{\circ} \mathrm{C}$. During 25 May cloud bands could be seen over land in the countries surrounding the Baltic Sea, indicating boundary layer rolls, as shown in Figure 1, which is a visual satellite image from 25 May from the MODIS (Moderate Resolution Imaging Spectroradiometer) Aqua satellite (https://modaps.modaps.eosdis.nasa.gov/services/ about/products/c6/MYD02QKM.html).

2.4. Simulation Setup. Simulations covering the period of the observations were run with the WRF (Weather Research and Forecasting) model, which is a mesoscale numerical weather prediction model used widely for research [28]. It can be run with a range of settings. Here, the MYNN2 boundary layer parametrization scheme is used, which has been shown to give good results in stable conditions [21, 29]. MYNN2 is a one-and-a-half-order closure scheme, where turbulent fluxes are a function of turbulent kinetic energy and stability. The model was run with several nested domains, as shown in Figure 2(a), for high enough resolution over the area of interest. The horizontal resolution was 27, 9, 3, and $1 \mathrm{~km}$, respectively, in each of the four domains. There were 48 vertical levels, with finer grid spacing near the surface in order to resolve processes in and directly above 
TABLE 1: WRF simulation settings used for this study.

\begin{tabular}{llc}
\hline Version & 3.5 & \\
\hline \multirow{2}{*}{ Resolution } & Horizontally: 4 domains with 27, 9, 3, 1 km resolution, respectively & \\
& 48 vertical levels with smallest grid spacing near ground & Dee et al. [30] \\
\hline \multirow{2}{*}{ Input } & ERA-Interim reanalysis every 6th hour & Nakanishi and Niino [31] \\
& No nudging & \\
& MYNN2 (Mellor-Yamada Nakanishi Niino level 2.5) boundary layer scheme & Tewari et al. [32] \\
PYNN surface layer scheme & Mlawer et al. [33] & Dudhia [34] \\
& Noah land surface scheme & [35] \\
& RRTM (Rapid Radiative Transfer Model) longwave radiation scheme & Thompson et al. [36] \\
\hline
\end{tabular}

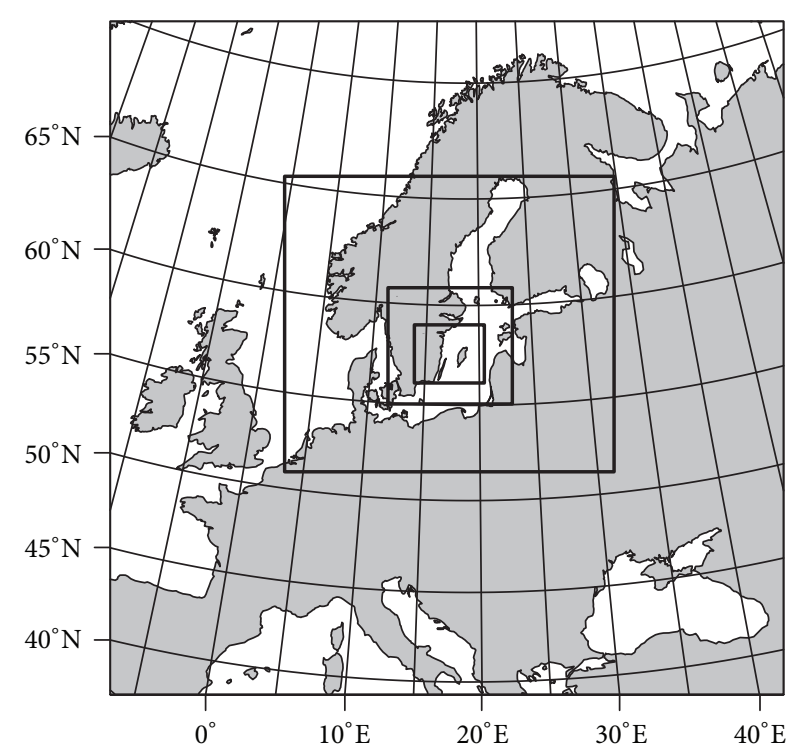

(a)

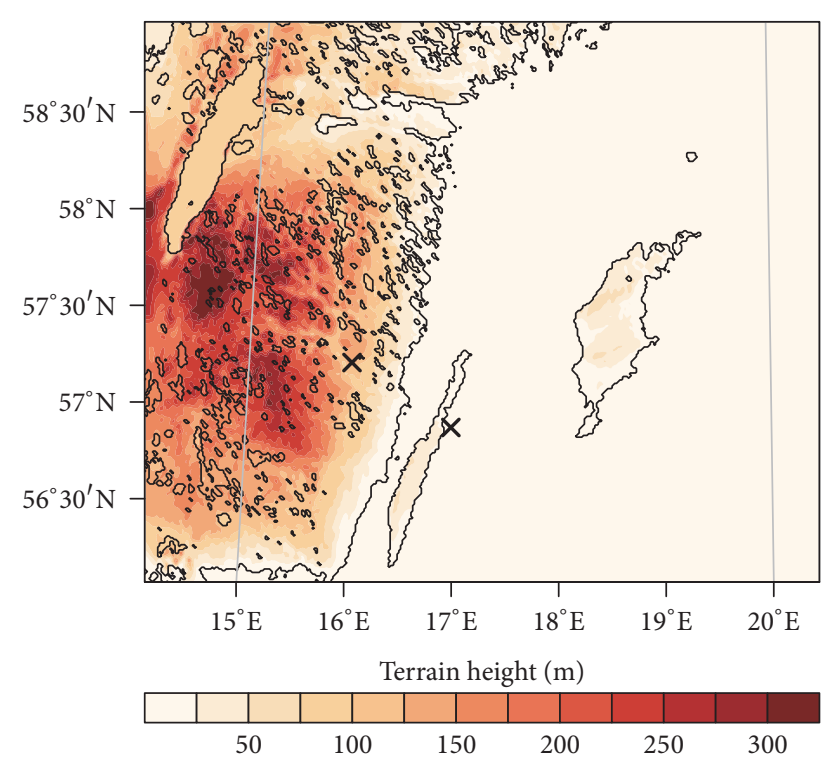

(b)

FIGURE 2: (a) WRF model domain setup, showing the outer domain and three nested inner domains marked by the black rectangles. (b) Terrain height in the innermost model domain. The crosses show the location of the two meteorological towers used in the study. The two largest islands in the domain are the islands of Öland (westernmost) and Gotland (easternmost).

the boundary layer. For example, there were 12 model levels below $100 \mathrm{~m}$, and 24 levels below $1000 \mathrm{~m}$. For a set of sensitivity simulations a smaller innermost domain was used, and also the resolution was modified when studying the model resolution dependence. The model was run for $30 \mathrm{~h}$ for each of the four studied cases, starting at 1800 UTC before the day of interest, and the first six hours were used as spin-up time. The model was forced by the ERA-Interim reanalysis at the outer domain every sixth hour. A summary of the settings is shown in Table 1. Results will be shown from the innermost domain, which is shown in Figure 2(b). The contours show the model topography of the site. There is a high plateau on the Swedish mainland, with terrain heights up to $300 \mathrm{~m}$. The island Gotland can be seen in the eastern part of the domain. The land-use category over land is forests over most parts of the area, with a roughness length of $0.5 \mathrm{~m}$.
2.5. Definition of Roll Characteristics. This section describes how different measures from the simulations and observations were defined. In order to be able to compare the simulation results from the different cases, two study areas were used, which were chosen because they represented regions of high roll activity over land and sea, respectively, and to avoid the influence of the island of Öland in the southern part of the domain. The study areas were used when calculating the wind speed and boundary layer wind shear and stability. The wind speed $(U)$ was taken at approximately a height of $450 \mathrm{~m}$, which was in the middle of the boundary layer. The wind shear was calculated as the difference in wind speed between the lowest model level and the model boundary layer height. Both wind speed and wind shear were calculated as an average inside the study area over land. The stability, expressed as the gradient Richardson number, was 


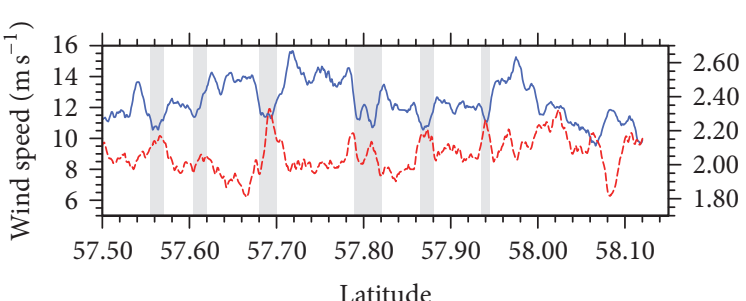

(a)

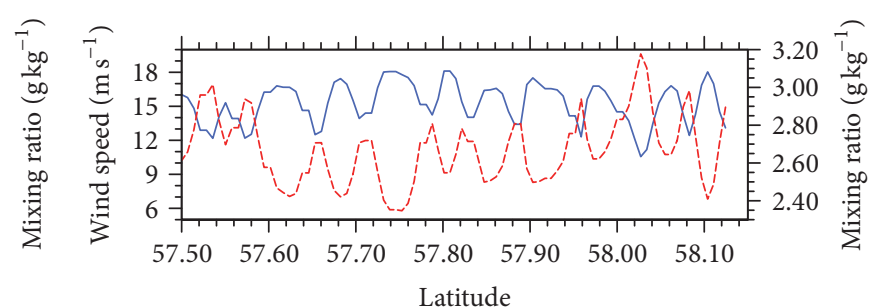

(b)

FIGURE 3: Horizontal wind speed (blue) and mixing ratio (red) from (a) a flight leg along the mainland coast on 3 May 1997 1512-1526 UTC and (b) the corresponding WRF data from 1500 UTC. The filled areas show regions were updraughts can be observed.

calculated as the median inside the respective study areas and was calculated according to

$$
\mathrm{Ri}_{\mathrm{G}}=\frac{g}{\bar{\theta}} \frac{d \theta / d z}{(d U / d z)^{2}},
$$

where $g$ is the gravitational acceleration, $\bar{\theta}$ is the mean potential temperature of the air layer, $d \theta / d z$ is the vertical potential temperature gradient, and $d U / d z$ is the vertical wind speed gradient, all calculated between the lowest model level and $\sim 140 \mathrm{~m}$. For the cases from 2011 the stability was also calculated from two meteorological towers maintained by Uppsala University. The first tower was $140 \mathrm{~m}$ high and placed inland in Ryningsnäs, around $35 \mathrm{~km}$ from the east coast of Sweden; see Figure 2(b) [37]. The Richardson gradient number, assumed characteristic for the mainland, was calculated between heights of 25 and $140 \mathrm{~m}$. The second tower was $50 \mathrm{~m}$ high and placed offshore, around $4 \mathrm{~km}$ outside Kårehamn on the east coast of Öland (Figure 2(b)). From here the sea surface stability was calculated between heights of 10 and $47 \mathrm{~m}$.

Boundary layer rolls are usually characterized by their wavelength $(\lambda)$, being the distance between wind speed maxima or minima, and the aspect ratio, being the ratio of the wavelength to roll height $(\lambda / h)$. The magnitude of the boundary layer rolls can also be given by their amplitude $(A)$. The wavelength and amplitude were calculated from crosssections of the horizontal wind speed anomaly aligned in the cross-roll direction. Three cross-sections were taken, one over land in the middle of the study area and two over sea, at the westernmost and easternmost edges of the study area. To calculate the wavelength the distance between adjacent wind speed maxima and the distance between adjacent wind speed minima were calculated and then averaged. Over land, maxima and minima were included only if they extended from the ground up to at least half the inversion height. Over sea, the rolls were less clear, which made the roll definition less accurate. The amplitude was calculated as half the difference in the horizontal wind speed between each of the adjacent rolls. The aspect ratio was calculated as the mean wavelength over the mean inversion height in the respective cross-sections.

As a measure of the strength of the boundary layer rolls the variance of the horizontal and vertical wind speed in the cross-roll direction was used. The mean value of variance was calculated inside the study areas as follows: at each latitude the cross-roll variance was calculated at every height, giving a height profile. An average was then taken over the maximum value of these profiles at each longitude.

Calculations were done on each hourly model output. The hourly values were then averaged over times with large-scale roll activity, that is, when rolls were observed in most parts of each of the three cross-sections. Over land, time steps were only included if the boundary layer rolls were fully developed, that is, if roll signatures could be seen in both the horizontal and the vertical wind speed.

\section{Results}

3.1. Boundary Layer Roll Characteristics from Aircraft Observations. During the first two cases, on 2 and 3 May 1997 aircraft measurements were conducted along the coasts of Sweden and Gotland. Figure 3 shows the horizontal wind speed and mixing ratio along the aircraft flight track along the Swedish mainland on 3 May 1997, flown at a height of $\sim 40 \mathrm{~m}$. Figure 3(a) shows measurements and Figure 3(b) shows model data from the corresponding location and time. Oscillating patterns could be seen in the wind speed with amplitudes of $1-2 \mathrm{~m} \mathrm{~s}^{-1}$, and in mixing ratio by $0.2 \mathrm{~g} \mathrm{~kg}^{-1}$. By visual inspection of these variables, evidence of updraughts could be seen in both wind speed and mixing ratio at several locations marked by the grey areas in the figure. These locations showed narrow peaks of decreased wind speed and increased relative humidity, and in between there were areas with relatively constant values with widths of around $10 \mathrm{~km}$. This indicates that the updraught regions were narrower than the downdraughts. Similar patterns could be seen from the other flight tracks (not shown). Fourier analysis was performed on the wind and humidity measurements along the flight tracks, showing a multitude of scales in the measurements, ranging from 3 to $15 \mathrm{~km}$ in wavelength. If the scales in both wind speed and relative humidity coincided this scale was taken to be the wavelength of the rolls. The amplitude was simply calculated as half the average difference between peak maximum and minimum values. The results are summarized in Table 2 together with the simulation result extracted along the same track as the flight measurements. Both measurements and simulations show that the wavelength tends to be smaller and the amplitude lower outside Gotland than outside the mainland. Also shown is the stability calculated from the aircraft slant profiles 


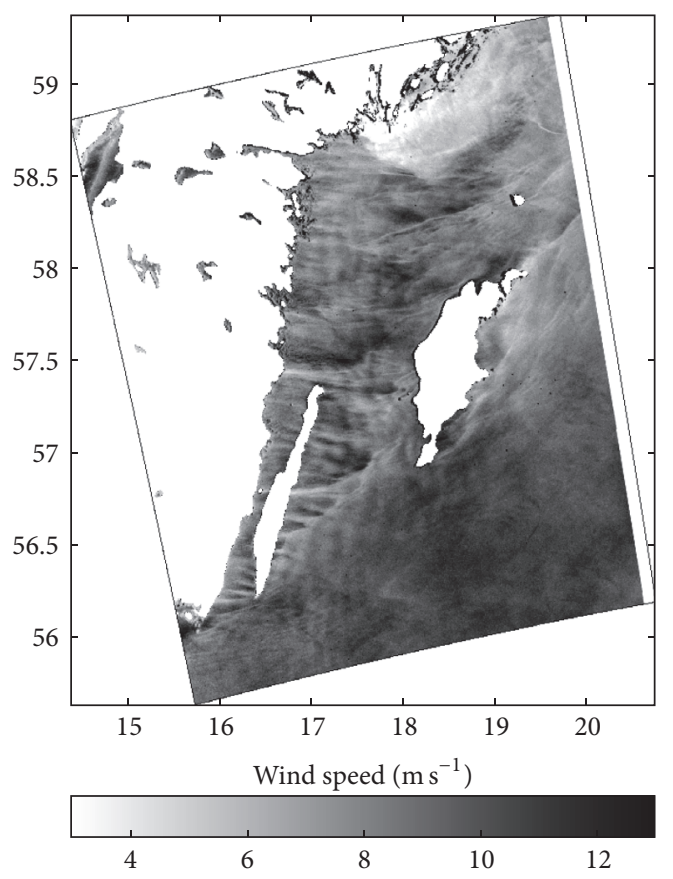

(a)

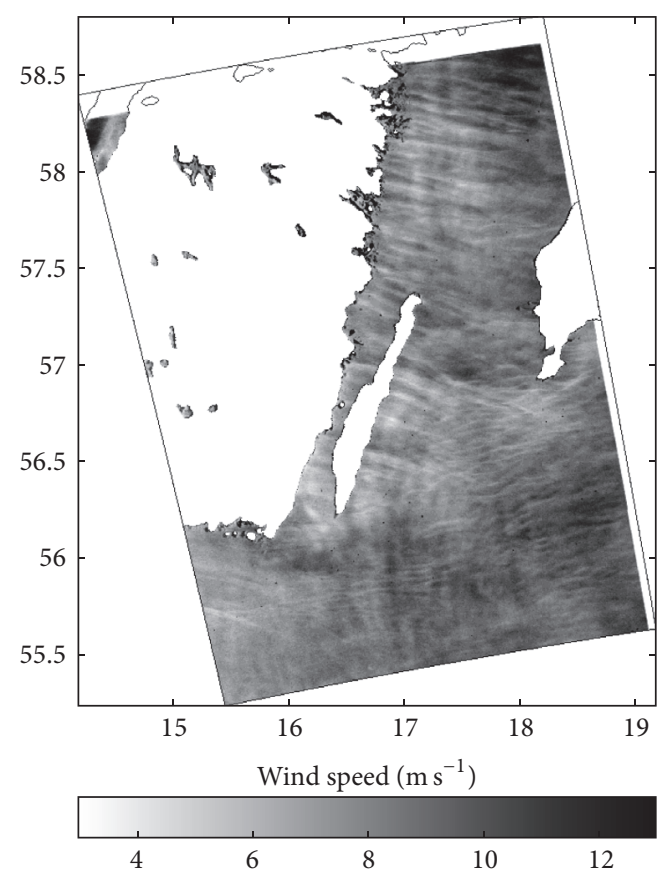

(b)

FIGURE 4: Processed SAR scenes acquired on (a) 17 May 2011, 2029 UTC, and (b) 25 May 2011, 2037 UTC, showing horizontal wind speed at $10 \mathrm{~m}$ height.

TABLE 2: Meteorological conditions and roll characteristics during two days from aircraft measurements and comparison with simulations along the flight legs.

\begin{tabular}{lcccc}
\hline \multirow{2}{*}{ Date } & \multicolumn{2}{c}{$02 / 05 / 1997$} & \multicolumn{2}{c}{$03 / 05 / 1997$} \\
& Obs. & WRF & Obs. & WRF \\
\hline $\mathrm{Ri}_{\mathrm{G}_{\text {sea }}}$ & 1.8 & 0.77 & 0.4 & 0.2 \\
$\begin{array}{l}\lambda \text {, outside mainland } \\
(\mathrm{km})\end{array}$ & 8.5 & $6-7,15.6$ & $10-13$ & 7.3 \\
$\begin{array}{l}\lambda, \text { outside Gotland } \\
(\mathrm{km})\end{array}$ & 6.6 & $6,8-9$ & $3.5,5$ & 6.2 \\
$\begin{array}{l}A, \text { outside mainland } \\
\left(\mathrm{m} \mathrm{s}^{-1}\right)\end{array}$ & $1.3 \pm 1.7$ & $1.2 \pm 0.8$ & $1.5 \pm 0.7$ & $2.3 \pm 0.5$ \\
$\begin{array}{l}A, \text { outside Gotland } \\
\left(\mathrm{m} \mathrm{s}^{-1}\right)\end{array}$ & $0.7 \pm 1.5$ & $0.6 \pm 0.5$ & $1.1 \pm 0.6$ & $1.1 \pm 0.7$ \\
\hline
\end{tabular}

and from WRF. Both model and observations suggest stable conditions, but to a larger degree in the observations. The difference is due to the mean profiles of temperature and wind speed having somewhat dissimilar shape in observations and simulations, which is not unexpected due to the different methods of calculation.

\subsection{Boundary Layer Roll Characteristics from SAR Images.} During the next two cases, on 17 and 25 May 2011 SAR images were available and are shown in Figure 4. Clear signatures of boundary layer rolls were seen as bands in the sea surface wind field extending out from the east coast of Sweden, in an area covering a south-north distance of approximately $250 \mathrm{~km}$. From the images each of the individual rolls could
TABLE 3: Meteorological conditions and roll characteristics during two days from SAR images and met towers.

\begin{tabular}{lcc}
\hline Date & $17 / 05 / 2011$ & $25 / 05 / 2011$ \\
\hline $\mathrm{Ri}_{\mathrm{G}_{\text {land }}}$ & -0.01 & -0.04 \\
$\mathrm{Ri}_{\mathrm{G}_{\text {sea }}}$ & 0.25 & 0.19 \\
$\lambda$, outside mainland $(\mathrm{km})$ & $9.2 \pm 2.2$ & $8.1 \pm 2.2$ \\
$A$, outside mainland $\left(\mathrm{m} \mathrm{s}^{-1}\right)$ & 2.0 & 1.5 \\
Length & 65 & 65 \\
\hline
\end{tabular}

be identified, with a total number of 27 rolls on 17 May and 29 rolls on 25 May, but with some gaps in between. The wavelength was calculated as the distance between each of these individual rolls, unless there was a gap in between. The wavelength and amplitude did not change with distance from the coast. Roll characteristics from the SAR images and stability calculated from the meteorological towers are shown in Table 3. The mean wavelength from the SAR scenes was 8$9 \mathrm{~km}$ with a standard deviation of $2.2 \mathrm{~m} \mathrm{~s}^{-1}$.

3.3. Boundary Layer Rolls Characteristics from Simulations. Figure 5 shows the horizontal wind speed from model simulations at approximately $100 \mathrm{~m}$ height for the four cases. The black lines in Figures 5(a) and 5(b) show the extent of the aircraft flight legs discussed in Section 3.1. The black rectangles in Figure 5(d) show the study areas used for calculations of roll characteristics. The figures were chosen at approximately the time and height when there was a maximum in roll strength over sea surface. The figures show 


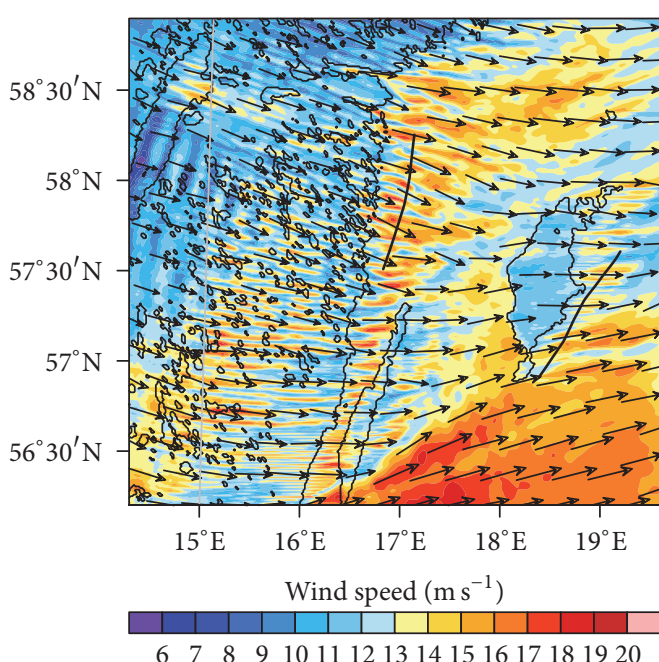

$\begin{array}{lllllll}6 & 7 & 8 & 9 & 1011 & 121314151617181920\end{array}$

(a)

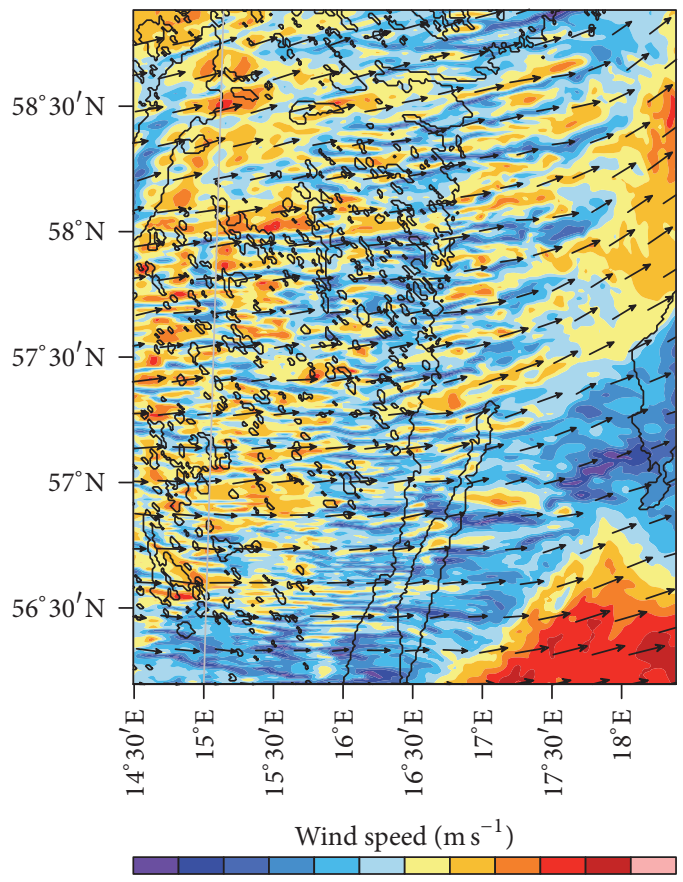

$\begin{array}{lllllllllll}10 & 11 & 12 & 13 & 14 & 15 & 16 & 17 & 18 & 19 & 20\end{array}$

(c)

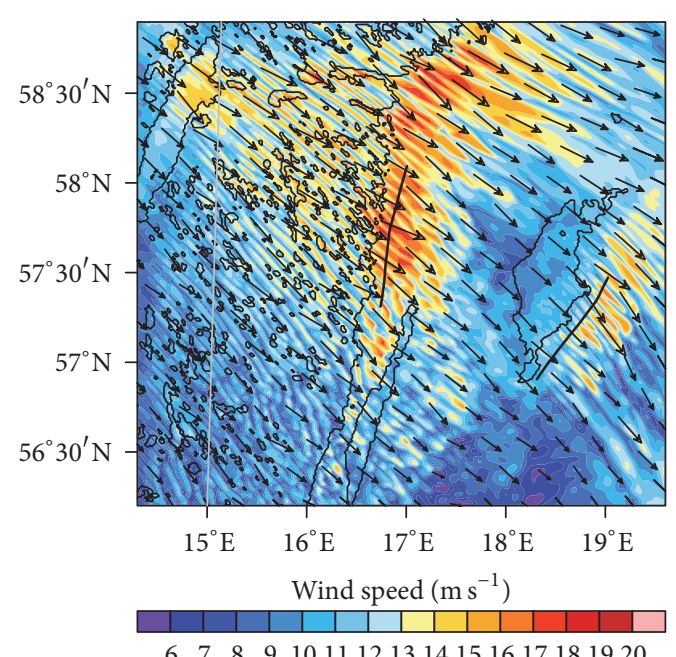

$\begin{array}{llllllll}6 & 7 & 8 & 9 & 1011 & 121314151617181920\end{array}$

(b)

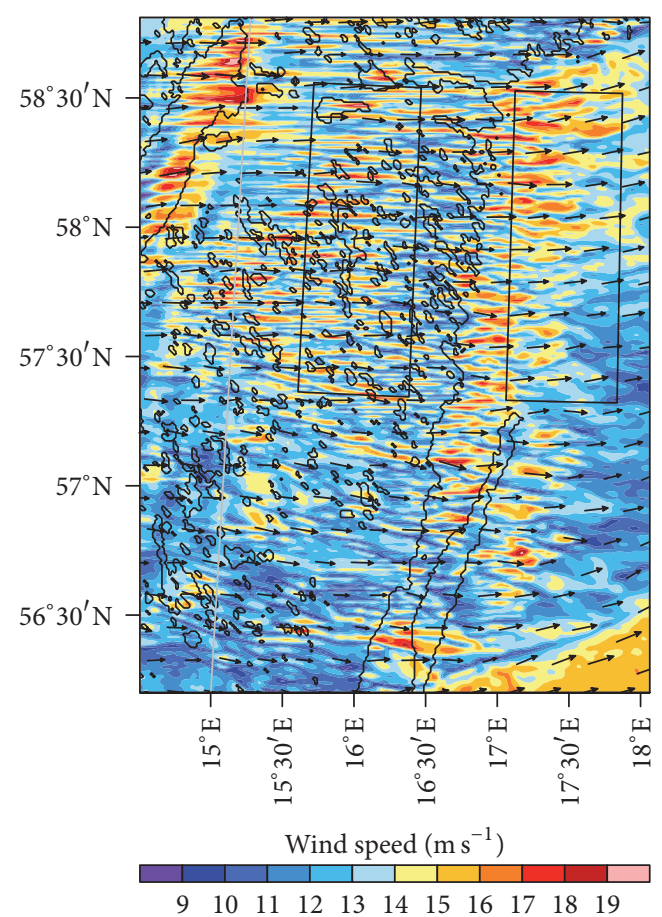

(d)

FIGURE 5: Wind speed from WRF simulations at $100 \mathrm{~m}$ height at (a) 2 May 1997, 1100 UTC, (b) 3 May 1997, 1100 UTC, (c) 17 May, 1600 UTC, and (d) 25 May, 13 UTC. The black lines in (a) and (b) show the location of the flight legs from these days. The black rectangles in (d) show the study areas over land and sea.

boundary layer rolls on all four days both over the mainland and extending out over the sea surface in the same area as the rolls in the SAR images. On 2 and 3 May 1997 streaks were also seen extending out from the island Gotland, showing that a distance of a few tens of kilometres in unstable conditions is enough for boundary layer rolls to be formed.

Some differences in roll characteristics were observed between the days. Table 4 presents the characteristics of each case in terms of weather situation and roll features, calculated as described in Section 2.5. The weather characteristics from model simulations were relatively similar on all days, with wind speeds of $15-17 \mathrm{~m} \mathrm{~s}^{-1}$ at $100 \mathrm{~m}$ height and substantial wind shear. The convection over land was strongest on 3 May, but the land-sea temperature gradient, and therefore the stability over sea, was strongest on 2 May. The clearest cases of boundary layer rolls were on 3 May and 25 May, when boundary layer rolls were forming early in the day, at $0700-0800$ UTC ( $-1 \mathrm{hr}$ from Swedish Normal Time), and remaining until the evening, 1800-1900 UTC. During 2 May 1997 and 17 May 2011, the boundary layer rolls were weaker, 
TABLE 4: Data from WRF simulations during the four days, showing meteorological conditions and roll characteristics taken from the study area as described in Section 2.5 .

\begin{tabular}{|c|c|c|c|c|}
\hline Date & $02 / 05 / 1997$ & $03 / 05 / 1997$ & $17 / 05 / 2011$ & $25 / 05 / 2011$ \\
\hline Observed rolls (UTC) & $0800-1700$ & $0800-1800$ & $1300-1900$ & $0700-1900$ \\
\hline Full rolls (UTC) & $0800-1700$ & 0800-1700 & $1300-1800$ & $0700-1600$ \\
\hline$U_{450}\left(\mathrm{~m} \mathrm{~s}^{-1}\right)$ & 15.2 & 15.3 & 15.5 & 17.1 \\
\hline Wind shear $\left(\mathrm{s}^{-1}\right)$ & 0.03 & 0.02 & 0.04 & 0.02 \\
\hline $\mathrm{Ri}_{\mathrm{G}_{\text {land }}}$ & -0.056 & -0.12 & -0.036 & -0.06 \\
\hline $\mathrm{Ri}_{\mathrm{G}_{\text {sea }}}$ & 0.7 & 0.15 & 0.82 & 0.2 \\
\hline$\lambda_{100}$, land $(\mathrm{km})$ & 7.5 & 7.0 & 7.8 & 5.1 \\
\hline$\lambda_{100}$, sea $1(\mathrm{~km})$ & 9.9 & 10.2 & 9.4 & 8.7 \\
\hline$\lambda_{100}$, sea $2(\mathrm{~km})$ & 29.6 & 31.7 & 31.7 & 33.5 \\
\hline Number of rolls land & 35 & 37 & 29 & 50 \\
\hline Number of rolls, sea 1 & 26 & 24 & 28 & 34 \\
\hline Number of rolls, sea 2 & 12 & 21 & 18 & 17 \\
\hline$A_{100}\left(\mathrm{~m} \mathrm{~s}^{-1}\right)$ & 1.5 & 1.7 & 1.6 & 1.9 \\
\hline$A_{100}$, sea $1\left(\mathrm{~m} \mathrm{~s}^{-1}\right)$ & 1.4 & 1.1 & 1.9 & 2.0 \\
\hline$A_{100}$, sea $2\left(\mathrm{~m} \mathrm{~s}^{-1}\right)$ & 0.7 & 1.0 & 0.9 & 1.1 \\
\hline$(\lambda / h)$, land & 4.8 & 3.9 & 5.4 & 3.8 \\
\hline$(\lambda / h)$, sea 1 & 7.5 & 6.7 & 7.7 & 7.3 \\
\hline$(\lambda / h)$, sea 2 & 22.5 & 20.8 & 26.0 & 30.1 \\
\hline Length $(\mathrm{km})$ & 80 & 100 & 80 & 80 \\
\hline
\end{tabular}

and on 17 May the boundary layer rolls formed in the afternoon, because of low wind speeds earlier in the day. Because the wind direction was southerly in the earlier part of the day it took a while before the rolls were advected out over the sea.

During the time of full rolls the wavelength and amplitude did not change to a large degree, which justified using a time average, in contrast to, for example, the study by Thurston et al. [19]. After the rolls started dissipating in the evening, there was a gradual transition until they completely disappeared. The SAR images shown in the previous section were from as late as 2030 UTC, when most of the rolls in the simulations had already dissipated. It is interesting that they were still clear and well-defined and with a large amplitude at this time in the evening, which suggests that the rolls can be even more persistent in reality than what is depicted in the model.

The mean wavelength over land was $5-8 \mathrm{~km}$, with a typical standard deviation at each time step of $2.5 \mathrm{~km}$. Compared to other observational studies this is relatively large. Many observational studies have found boundary layer rolls of scales $2 \mathrm{~km}[3,6,38]$ and similar results from LES models $[5,15]$. However, boundary layer rolls with larger wavelengths have also been observed in many cases. For example, Thurston et al. [19] observed boundary layer rolls with $7-9 \mathrm{~km}$ wavelength under strong convection over the Australian continent.

There was quite a good agreement between model and observations in terms of wavelength near the coast but less agreement further out. In the model the wavelength estimate increased over sea because rolls were less prone to form, with the result that some rolls would survive a longer distance while others would dissipate. At the outer edge of the study area only a few rolls were still seen with the result that the wavelength estimate increased. However, far out over the sea this distance was not always characteristic of the true wavelength since the roll circulations were weak and unclear and sometimes with gaps in between the rolls. In comparison, the observed rolls at this distance were clearly visible and straight, which made it possible to calculate the distance between each of the adjacent rolls.

The mean amplitude of the horizontal wind over land was $1.5-2.0 \mathrm{~m} \mathrm{~s}^{-1}$ with a typical standard deviation of $0.3-0.7 \mathrm{~m} \mathrm{~s}^{-1}$ at each time step. The strongest rolls had amplitudes of up to $4 \mathrm{~m} \mathrm{~s}^{-1}$. Wind speed anomalies in downdraughts were larger than in updraughts. The amplitude given in Table 4 is a measure of the wind speed anomalies that the rolls give rise to rather than the speed of the roll circulation, which more readily could be given by the latitudinal wind variations. As the rolls extended out over sea surface the amplitude decreased from the land value towards zero.

The roll direction was approximately aligned with the mean wind direction in the boundary layer. The extent of the rolls from the coastline was up to $80 \mathrm{~km}$ on three of the days, which is the distance to the island Gotland in the east-west direction. On 3 May 1997 the wind direction was northwest, which enabled the longer distance of $100 \mathrm{~km}$. The maximum extent varied throughout the days though, and the minimum extent was commonly $25-30 \mathrm{~km}$.

To explain the forcings and maintenance of the rolls the remainder of the study will focus on the case from 25 May 2011, because SAR images were available and the simulations showed a full diurnal cycle of boundary layer rolls. Figure 6 shows two vertical cross-sections in the cross-roll direction at 1400 UTC, one over land and one over water, taken in the middle of the respective study areas. The black lines show 


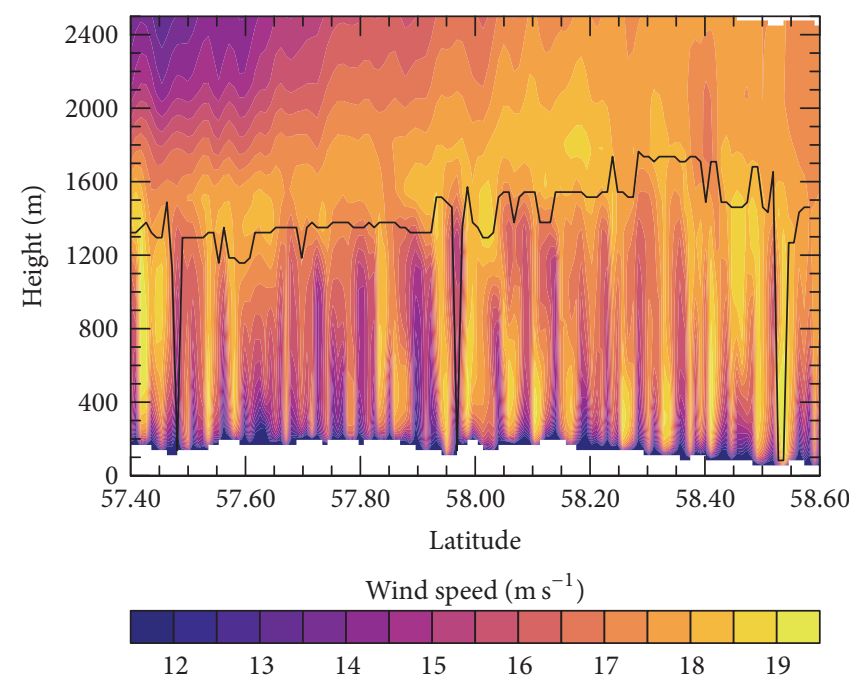

(a)
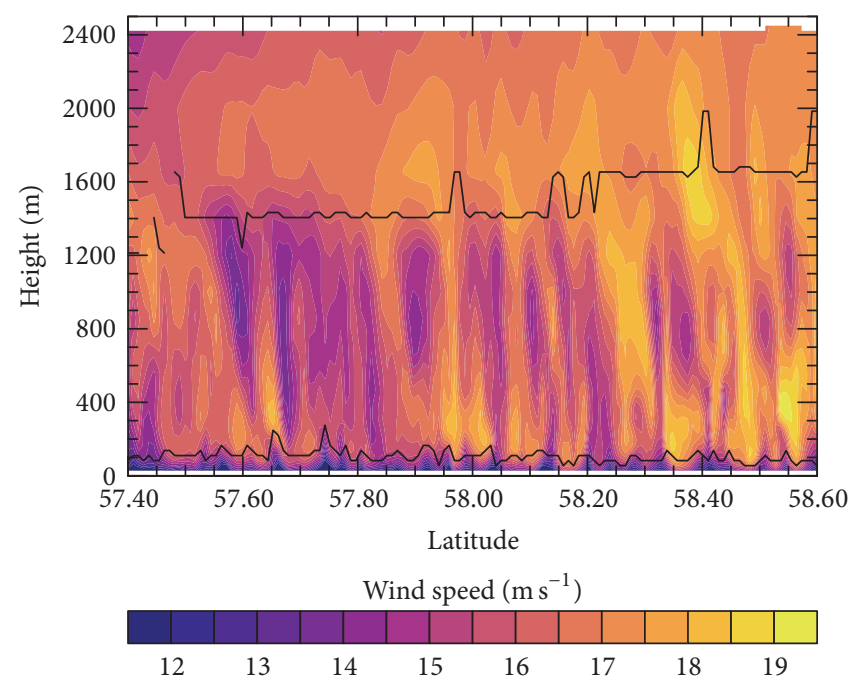

(b)

FIGURE 6: Vertical south-north cross-section of wind speed from model simulations at 1400 UTC (a) over land at longitude 15.9 and (b) over sea at longitude 17.4. The height of the ground surface can be seen from the lower boundary. The black lines show the height of the inversion(s).

the inversion height, which is defined as the height where the potential temperature gradient first becomes larger than $0.004 \mathrm{~K} \mathrm{~m}^{-1}$. In the cross-sections over sea there were two pronounced inversions, and therefore the inversion height was calculated separately below and above $\sim 400 \mathrm{~m}$ height. Below $400 \mathrm{~m}$ the inversion height instead corresponded to the highest height where $d \theta / d z>0.004$. As can be seen, the boundary layer rolls were mostly confined inside the boundary layer over land, with a model boundary layer height of 1200-1400 m, approximately coincident with the inversion height. The roll direction was approximately aligned with the mean boundary layer wind direction at all heights. Over sea the boundary layer rolls were evident both in the residual layer and in the boundary layer. The rolls started turning with height due to increased wind veer, and the structure became less well-defined. Note also that since the coastline is not exactly aligned in the south-north direction, but somewhat slanting, the left parts of the oversea cross-sections are further out over the sea than the right parts, which is manifested in the larger inversion height in Figure 6(b).

As seen from Table 4 and Figures 5 and 6, there was a large variability in wavelength and amplitude of the rolls, from 2 to $20 \mathrm{~km}$. This implies that there must be several processes acting on the boundary layer rolls as a result from the inhomogeneities in terrain, roughness, and heating and also from meandering of rolls. It seems likely that rolls merge to form larger sized rolls, whereas others dissipate quickly. This process creates many different scales over the studied areas. However, the size of the phenomena that can be resolved accurately by weather prediction models is $\sim 8$ times the model resolution. Due to the limited horizontal resolution of $1 \mathrm{~km}$ rolls with a few kilometres' wavelengths will not be adequately described, and there may be structures also on smaller scales which are not resolved. The mean value of

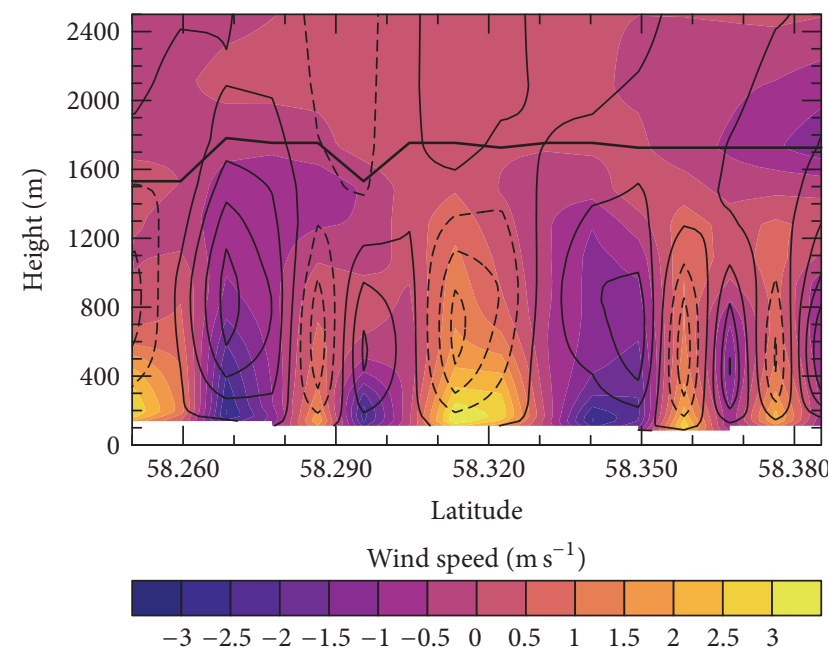

FIGURE 7: Vertical south-north cross-section from model simulations at 1400 UTC of horizontal wind speed (colour fill) and vertical wind speed (black contours) at longitude 15.9. The black contours are from -0.9 to 0.9 by 0.3 , where filled lines are positive values and dashed lines are negative. The thick black line shows the height of the inversion.

the wavelength may therefore be overestimated, but it is still useful to show the differences between the simulated days.

Figure 7 is a close-up of Figure 6(a), but instead showing the wind speed anomaly. Clear and correlated patterns of horizontal and vertical wind speed are evident, with lower horizontal wind speed in the updraughts and higher in the downdraughts. The maximum horizontal wind variations are found near ground and the maximum vertical wind variations in the middle of the boundary layer, which is characteristic of boundary layer rolls. 


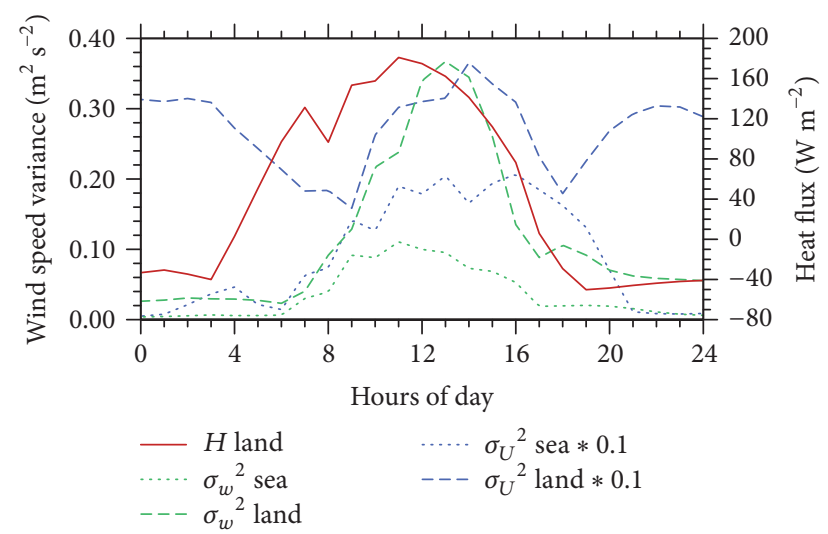

FIgURE 8: Time evolution of heat flux $(H)$, variance of cross-roll vertical wind $\left(\sigma_{w}^{2}\right)$, and horizontal wind speed $\left(\sigma_{U}^{2}\right)$ on 25 May 2011 from model simulations. Dashed lines show values over land and dotted lines show values over water.

3.4. Creation Mechanism of Boundary Layer Rolls. Thermal instability likely plays an important role in the formation of these rolls. This can be seen by studying the diurnal evolution of roll occurrence and heat flux from the model simulations. Figure 8 shows the heat flux over land, which can be considered a measure of the convection and buoyancy generated turbulence and the cross-roll variances of the vertical wind speed $\left(\sigma_{w}^{2}\right)$ and horizontal wind speed $\left(\sigma_{U}^{2}\right)$, calculated on the $1 \mathrm{~km}$ model grid as explained in Section 2.5.

It can be seen that there was a clear diurnal cycle of $\sigma_{w}^{2}$, similar to the diurnal cycle of heat flux, but starting to increase approximately three hours after the heat flux became positive. It started decreasing simultaneously with the heat flux, and had almost disappeared at 1700 UTC, when the heat flux became negative. During the time of increased $\sigma_{\mathrm{w}}^{2}, 0700-1600 \mathrm{UTC}$, boundary layer rolls were clearly seen over land, indicating that the likely creation mechanism was thermal instability. The horizontal wind variance, on the other hand, started to increase at approximately the same time as the heat flux but was persistent for a longer time. Over sea, elevated values of $\sigma_{U}^{2}$ were evident until 2100 UTC. The shape of the $\sigma_{w}^{2}$ curves over land and sea has a somewhat dissimilar shape, where the variance over sea peaks earlier in the day. However, it is likely that the increasing variance over sea around this time of day is due to the passing of a trough, and not to an increase in roll activity. During the period 1700-2000 UTC, streaky structures could be seen only in the horizontal wind speed fields.

Results from previous observational studies have indicated several different criteria for roll formation. Some studies propose that the wind speed or wind shear should exceed a certain limit, for example, wind speed above $5.5 \mathrm{~m} \mathrm{~s}^{-1}$ and shear larger than $2 \cdot 10^{-2} \mathrm{~s}^{-1}$ [4]. Another criterion suggests restrictions on the Obukhov length scale, $L$. For example, in the review paper by Etling and Brown [39] it is mentioned that rolls form when $-z_{i} / L<5$ and cells when $-z_{i} / L>25$ with a mixture of rolls and cells in between. Smedman [13] found roll signatures only when $-z_{i} / L>5$. However, boundary layer rolls have been observed with instabilities of $-z_{i} / L>100$ [6]. In this case the simulations show a mean boundary layer wind shear of 0.02-0.04 during the day and the wind speed through most of the boundary layer is $15-17 \mathrm{~m} \mathrm{~s}^{-1} . z_{i} / L$ is -3 to -6 . The values of these parameters are typical for roll formation during thermal instability.

As mentioned, for dynamic instability to be the cause of boundary layer rolls there needs to be an inflection point in the cross-roll wind speed profile. In this case the boundary layer was well-mixed over land, which created an inflection point only at the top of the boundary layer. Since we found no evidence of a large-scale roll formation around the top of the boundary layer and the roll activity followed the variations of heat flux, it is likely that dynamic instability was not the main creation mechanism in the model simulations. Over the sea surface no clear inflection point was observed either in the boundary layer or in the residual layer in the area where rolls were located. Here, however, the roll structure was much less clear and it was not obvious which mechanisms were of importance. In some cases the roll signatures were strongest at higher altitude, even though this was not so common. Dynamic instability could then possibly act to maintain rolls over sea surface, though not with the same strength as the roll formation over land.

3.5. Maintenance of Boundary Layer Rolls over Water. According to the discussion in the previous section the roll activity can be divided into two different stages: 0700-1600 UTC, when rolls were forming over land and roll structures could be seen in both the vertical and horizontal wind, and 1700-2100 UTC when streaky structures were seen only in the horizontal wind. Figure 9 shows $\sigma_{U}^{2}$ and $\sigma_{w}^{2}$ at three times, picturing the time of dissipation. In these panels the approximate inversion height, calculated as explained in the previous section, is also shown. To the right the streaky structures in the horizontal wind speed can be seen in the area over which the variance is calculated.

From Figures 9(a) and 9(d) it can be seen that roll activity over land was confined inside the boundary layer. The boundary layer over land was well-mixed and capped by an inversion at $\sim 1300 \mathrm{~m}$ height above ground. The maximum in $\sigma_{w}^{2}$ was at $\sim 500 \mathrm{~m}$ height, which was around half the boundary layer height, and $\sigma_{U}^{2}$ had its maximum at $\sim 100 \mathrm{~m}$ height, similar to what was shown in the cross-section in Figure 7. Over sea, there was a stable layer in the lowest $\sim 150 \mathrm{~m}$, and above this there was a residual layer. At 1400 UTC $\sigma_{w}^{2}$ started decaying at the coastline when the stratification became stable but did not dissipate until longitude 17.4, or at approximately $35 \mathrm{~km}$ outside the coast. Similar behaviour was observed for $\sigma_{U}^{2}$ (Figures 9(b) and 9(e)). Over sea, the height and strength of $\sigma_{U}^{2}$ decreased, but it did not dissipate until around $60 \mathrm{~km}$ outside the coast. The subgrid scale turbulent kinetic energy (TKE), on the other hand, dissipated quickly and was almost zero at around $10 \mathrm{~km}$ from the coastline. This is consistent with the study by Vickers et al. [40] where it was shown from observations that advected turbulence is maintained for less than $10 \mathrm{~km}$ offshore. Consequently, there was advection of coherent structures in the wind field during 


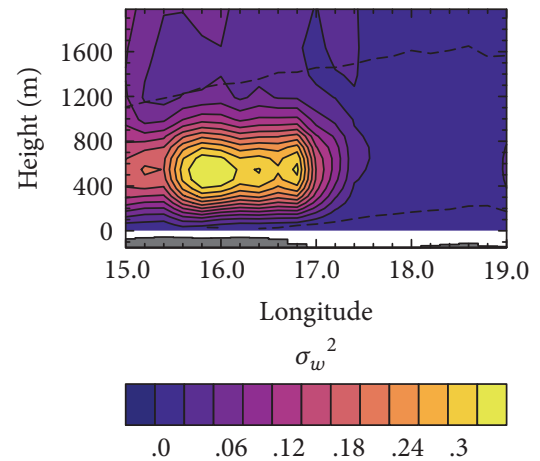

(a)

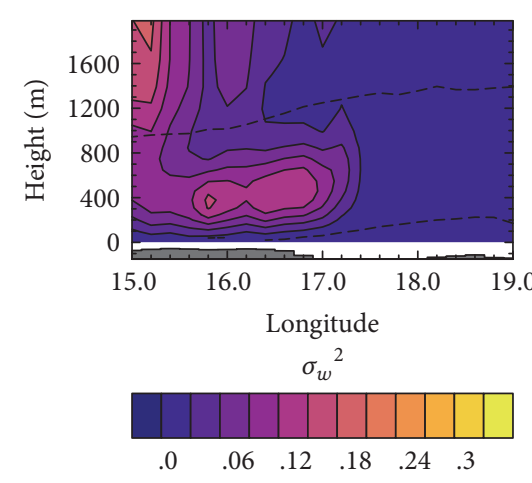

(d)

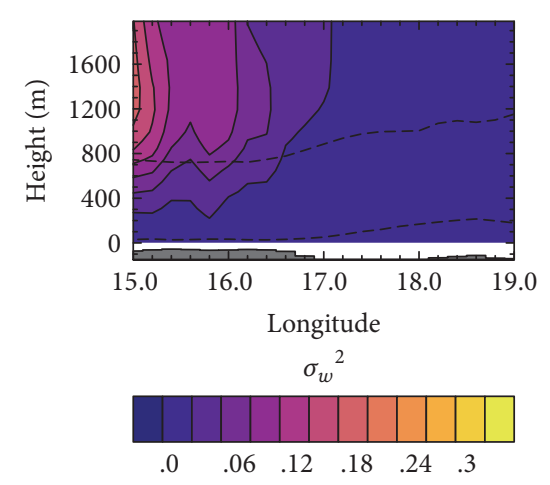

(g)
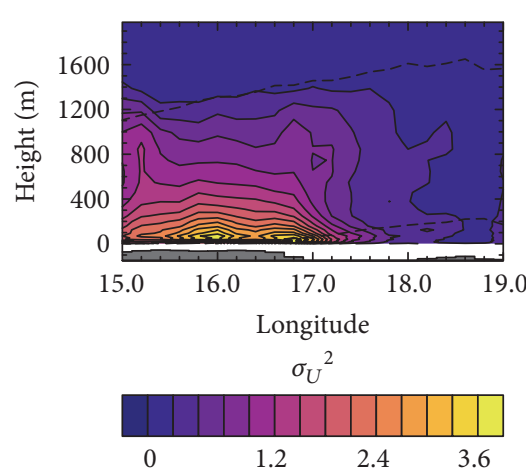

(b)

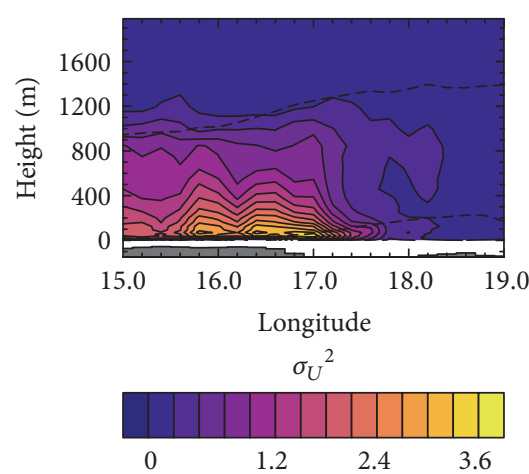

(e)

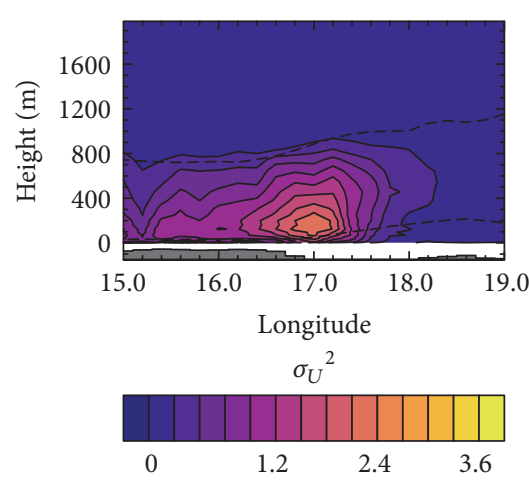

(h)

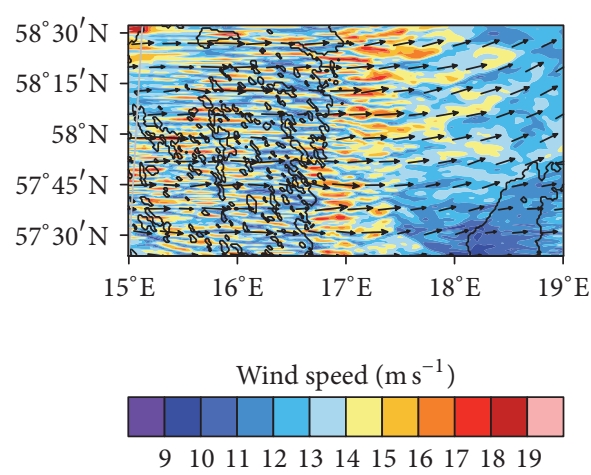

(c)

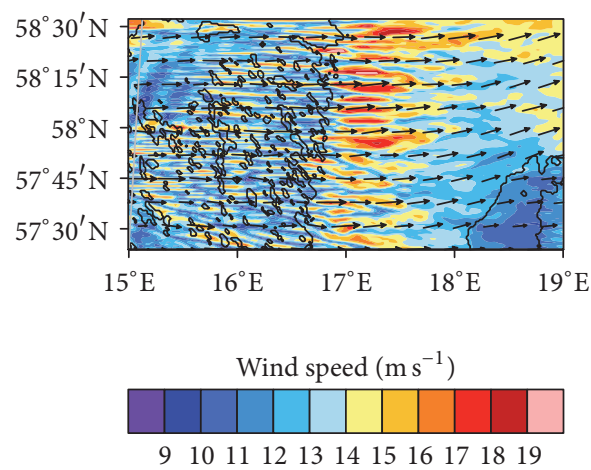

(f)

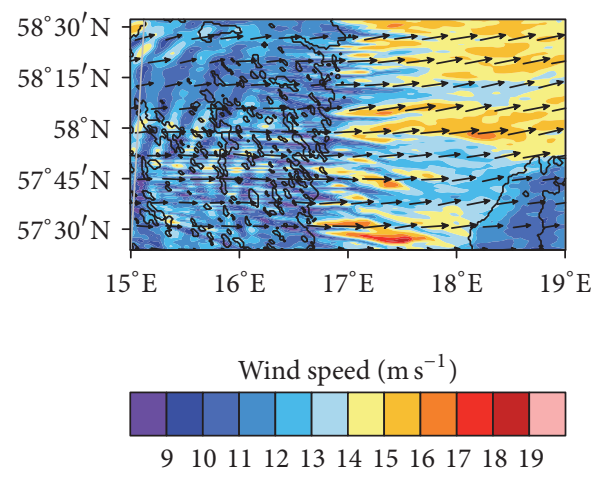

(i)

FIGURE 9: (a, b, d, e, g, h) show the cross-wind variance of ( $a, d, g)$ vertical wind speed and (b, e, h) horizontal wind speed. (c, f, i) show the horizontal wind field at approximately $100 \mathrm{~m}$ height in the area over which the variance is calculated. The figures are from times (a, b, c) 1400 UTC, (d, e, f) 1600 UTC and (g, h, i) 1800 UTC. The dashed lines in (a, b, d, e, g, h) show the approximate inversion height below and above $400 \mathrm{~m}$ height. The grey area below the plots shows the average ratio of land at each latitude.

the day, which were more persistent than convective eddies. The convection and the coherent structures therefore may be governed by different time scales.

The decay of convective turbulence in the afternoon has been investigated in several studies. Afternoon transitions in midlatitudes can take place over several hours, but in this case the change in forcing is very abrupt, changing from unstable to stable across the coastline. This bears some resemblance to the LES study by Niewstad and Brost (1986), where it was shown that the decay of convective turbulence after an abrupt removal of surface heat flux could be described by the eddyturnover time:

$$
t_{*}=\frac{z_{i}}{w_{*}}
$$

where $z_{i}$ is the boundary layer height and $w_{*}=\left(g z_{i} \overline{w^{\prime} \theta^{\prime}}\right)$ $\left.\rho c_{p} \theta\right)^{1 / 3}$ is the convective velocity. The turbulence would stay approximately constant for one eddy-turnover time and then decay according to a power law. Using this relation, the eddyturnover time in this case is approximately 13 minutes. With an advective wind speed of $17 \mathrm{~m} \mathrm{~s}^{-1}$ (at $900 \mathrm{~m}$, which is at the height of the roll maximum) this implies an advective length scale of only $13 \mathrm{~km}$, which is much shorter than the advection distance in this study. 
In conformity with this study, LES simulations performed by Glendening [5] showed that the time scale of roll-like structures was significantly longer as compared with the convective time scale. A roll-overturning time scale was proposed

$$
\tau_{R}=\frac{1}{4}\left(\frac{\lambda_{R}}{\sigma_{v_{R}}}+\frac{2 z_{i}}{\sigma_{w_{R}}}\right),
$$

where $\lambda_{R}$ is the roll wavelength, $\sigma_{v_{R}}$ and $\sigma_{w_{R}}$ are the maximum values taken from the profiles of standard deviations of the cross-roll latitudinal horizontal and vertical velocity, respectively, and $z_{i}$ is the boundary layer height. This time scale uses a measure of the roll kinetic energy, expressed by the vertical and the cross-roll standard deviation at the roll scales, which we take to be the resolved motions on the 1-km grid, as opposed to the unresolved convective turbulence. Using this relation, with values of $\lambda_{R} \approx 5.1 \mathrm{~km}, \sigma_{v_{R}} \approx 1.1, z_{i} \approx 1300 \mathrm{~m}$, and $\sigma_{w_{R}} \approx 0.6$, gives $\tau_{R}=37 \mathrm{~min}$, which is substantially longer than the eddy-turnover time. With an advection speed of $17 \mathrm{~m} \mathrm{~s}^{-1}$, the distance corresponding to $\tau_{R}=37 \mathrm{~min}$ was $38 \mathrm{~km}$, which agrees well with our model simulations. However, in this relation it is assumed that the wavelength and amplitude of the rolls are uniform in the cross-roll direction, which was clearly not the case here. Taking into account the uncertainty in wavelength and amplitude gives rise to an uncertainty of $\sim \pm 15 \mathrm{~min}$. In the simulation by Glendening [5] there was also no change in time in the surface forcing, as opposed to this study where conditions changed from unstable to stable, therefore inhibiting growth of new rolls. Another effect when the rolls are advected over sea is the frictional decoupling and an increased wind veer, which may augment the dissipation of the rolls by deflecting them more towards the right with height, therefore transforming the roll structure. This deflection can be seen in in Figure 6(b). The timescale also assumes that the roll circulation is purely 2dimensional, which is an oversimplification. The rolls have a 3-dimensional nature because of the difference in horizontal wind speed between updraught and downdraught regions.

Figure $9(\mathrm{~g})$ shows that at 1800 UTC the $\sigma_{w}^{2}$ maximum inside the boundary layer had completely died out, consistent with Figure 8 . Another variance maximum was seen in the upper left of Figures 9(d) and 9(g), which was connected to gravity wave activity. The boundary layer over land had cooled, with a residual layer being created. At this time horizontal wind variations were still evident. The location of the maximum variance had moved out over sea surface, and the maximum value had decreased. Streaky structures could be seen in the horizontal wind at 1800 UTC, and a few streaks could also be seen at 2000 UTC, but later than this no streaks were distinguishable anymore. From 1700 UTC and onwards the structures could no longer be called boundary layer rolls but were leftovers from the convection earlier in the day, advected by the wind. During the evening, the advection distance, as viewed from above from 2-dimensional plots, was increasing. Some of the streaky structures stretched all the way to the island of Gotland, a distance of $80 \mathrm{~km}$ corresponding to an advection time of approximately 75 minutes.
TABLE 5: Stability and roll characteristics from simulations using different SSTs.

\begin{tabular}{lccc}
\hline Simulation & Default & SST decrease -2 & SST decrease -4 \\
\hline $\mathrm{Ri}_{\mathrm{G}_{\text {land }}}$ & $-2.5 e-2$ & $-2.3 e-2$ & $-3.6 e-3$ \\
$\mathrm{Ri}_{\mathrm{G}_{\text {sea }}}$ & 0.036 & 0.065 & 0.078 \\
$\lambda_{100}(\mathrm{~km})$ & 5.1 & 5.1 & 6.0 \\
$A_{100}\left(\mathrm{~m} \mathrm{~s}^{-1}\right)$ & 1.9 & 1.9 & 1.6 \\
\hline
\end{tabular}

TABLE 6: Roll characteristics from simulations using different resolutions on 25 May 2011.

\begin{tabular}{lccc}
\hline Resolution $(\mathrm{m})$ & 2250 & 750 & 562.5 \\
\hline$\lambda_{100}$, land & 9.5 & 5.5 & 4.2 \\
$A$ & 1.4 & 1.8 & 1.9 \\
\hline
\end{tabular}

3.6. Sensitivity to Model Setup. To understand the sensitivity of the boundary layer rolls to model setup a number of additional simulations were performed. In order to investigate how important the stratification over sea surface was for the maintenance of boundary layer rolls two additional simulations were performed in which the SST (Sea Surface Temperature) over the southern Baltic Sea was decreased by 2 and 4 degrees, respectively. This increased the stability over the sea but at the same time influenced the air temperature in the whole inner domain, also decreasing the instability over land. Table 5 shows the results using different stabilities and Figure 10 shows the horizontal wind speed anomaly in a small area of the domain. A change of -2 degrees in the SST mostly had an effect on the stability over the sea surface, and the changes in amplitude were small. Decreasing the SST by 4 degrees had an impact also on the stability over land, and this was likely the reason why the roll strength decreased.

Despite the weaker rolls they were still advected across the coast the same distance, showing that the strength of the stability did not to a large degree influence the advection. This suggests that the dissipation of the boundary layer rolls is not governed by the ambient conditions to any large degree but by an inherent dissipation length scale depending on the size and strength of the rolls.

The boundary layer rolls have wavelengths of on average $5-8 \mathrm{~km}$, which is at the limit of what can be captured by a horizontal resolution of $1 \mathrm{~km}$. Therefore, a set of simulations were made with different horizontal resolutions to investigate if the size of the rolls would decrease with finer resolution. The two outer domains were the same as in the default simulations, but the third domain instead had a resolution of $2.25 \times 2.25 \mathrm{~km}$ and the innermost domain a resolution of $750 \times 750 \mathrm{~m}$ in the first simulation and a resolution of $565.5 \times 565.5 \mathrm{~m}$ in the second simulation. Table 6 shows the wavelength and amplitude of these simulations along a transect taken at the same locations as in previous analysis. The largest difference was between the domain with $2.25 \mathrm{~km}$ resolution and the domain with $750 \mathrm{~m}$ resolution, where the wavelength decreased by $\sim 4 \mathrm{~km}$ when increasing the resolution. When increasing the resolution to $562.5 \mathrm{~m}$ the 


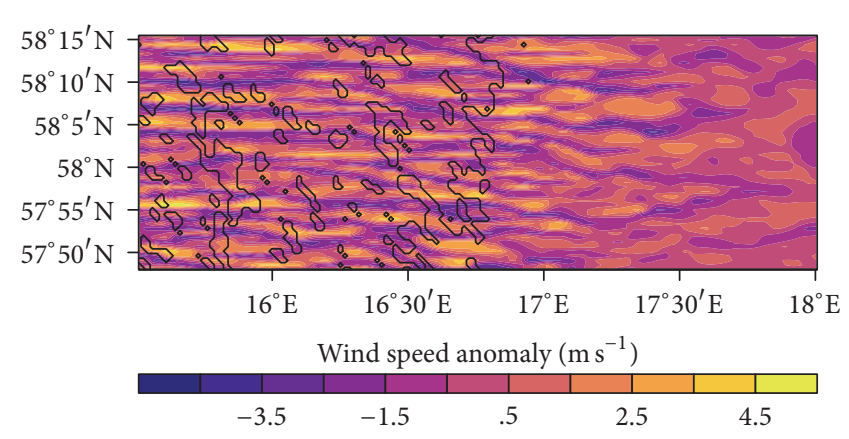

(a)

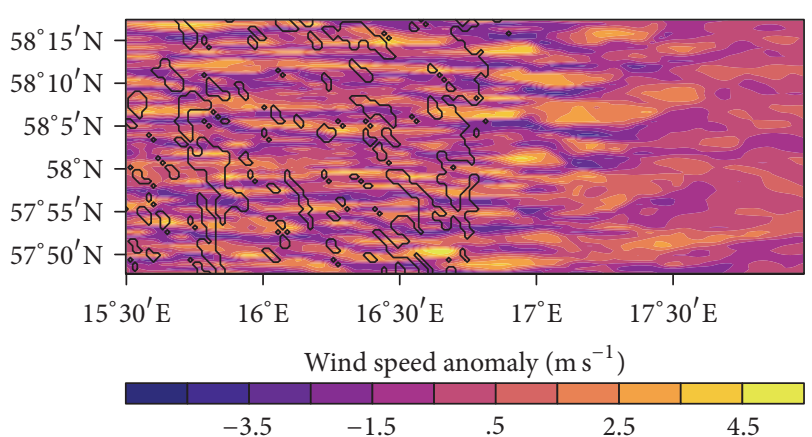

(b)

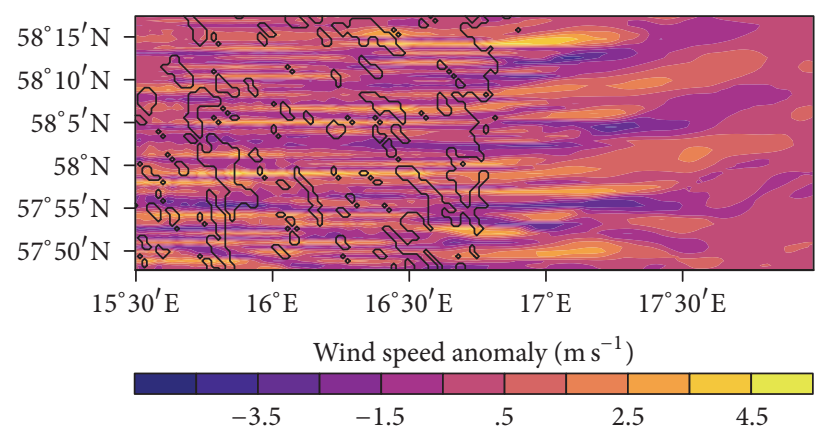

(c)

FIGURE 10: Horizontal wind speed anomaly from simulations with different sea surface temperatures at 14 UTC. (a) Default. (b) SST- ${ }^{\circ} \mathrm{C}$. (c) SST $-4^{\circ} \mathrm{C}$.

changes in wavelength and amplitude were still notable but smaller.

From the table it is clear that there is a strong resolution dependence of the boundary layer rolls characteristics. This decreases the reliability of the results for two reasons. One is that mesoscale secondary circulations can appear when increasing the resolution when they are not necessarily real. According to Ching et al. [41] this could be because the profiles of potential temperature are in general too unstable compared to measurements, which could force excessive convection which could act to create boundary layer rolls or cells. The available measurements of temperature profiles over land in this case were not enough to draw conclusions on whether this can be the case here. On 25 May 2011 boundary layer rolls were seen in the visible satellite imagery and also in the SAR images, suggesting that this is a real phenomenon. The rolls were also seen at all resolutions finer than $9 \mathrm{~km}$ and could also vaguely be observed at $9 \mathrm{~km}$ resolution. Observational studies also show that boundary layer rolls are often observed during these types of atmospheric conditions, as mentioned in Section 3.4. It is thus likely that these phenomena are real, and therefore the second problem is that the scale of the boundary layer rolls is unknown. Studies have shown that when increasing the resolution to subkilometre scale roll amplitude and growth rate grows [41], and roll circulations can turn into more unorganized convective patterns $[18,19]$, which suggests that it can not safely be said that an increased resolution would improve the performance of the simulations. It is still unknown exactly how the boundary layer rolls interact with subgrid scale turbulence, and therefore it is not possible to say at which resolution the portrayal of rolls is most accurate. The simulations in this study should thus be regarded qualitatively and looking at the large-scale extent and connection to weather patterns rather than on the detailed structure of the rolls themselves.

\section{Discussion and Conclusions}

In this study four cases of boundary layer rolls have been studied, which were observed in and above the marine boundary layer during stable conditions. Model simulations show that the boundary layer rolls were created over the convective land surface and advected out over the colder sea surface, being maintained for several tens of kilometres in the stable boundary layer and the above residual layer. In other studies of boundary layer rolls over stable sea surface the formation mechanism has been attributed to dynamic instability.

The results have been compared with two different types of measurements: aircraft measurements and satellite SAR images, which confirm the model results over sea surface. The agreement was relatively good in terms of wavelength, amplitude, and advection distance over the sea surface. However, because of the resolution dependence of the roll circulations, there is an uncertainty in the roll strength and size.

Some differences between the four modelled days were observed. During all days the wind speed was large, in the range $15-17 \mathrm{~m} \mathrm{~s}^{-1}$ in the middle of the boundary layer. On 
2 May 1997 the conditions were the most stable and rolls less pronounced. On 25 May 2011 the wind speed was largest and the roll wavelength smallest. Thus there appears to be an optimum in weather conditions for roll formation, with large wind speeds and moderate unstable conditions. From this limited study no further conclusions regarding what governs this speculated optimum for roll formation can be drawn.

Sensitivity simulations showed no dependence of roll characteristics with the over-ocean stability. However, when the conditions became more neutral the rolls became more linear and weaker. This indicates that it is mainly the upwind land conditions that govern the roll characteristics and the advection distance over sea.

During three of the four days, a complete diurnal cycle of roll formation could be observed in model simulations. Other studies $[12,19,42]$ have reported that boundary layer roll was the first type of convective pattern, which later in the day would change into cellular or unorganized convection due to increasing instability. In this case boundary layer rolls were observed in model simulations during the whole convective period throughout the day. After the convection had stopped, streaky structures could still be seen in the horizontal wind speed. Thus there appears to be a delay both in time and in space before the rolls completely dissipate. The delay in time, we argue, is due to an inherent property of the rolls and their advection speed and is taking place during the daytime when rolls are fully developed. The delay in time is observed to happen in some of the cases, in the evening after the roll forcing has stopped. These structures can bear some analogy to island wakes, which persist in stable or neutral conditions due to the low ambient turbulence intensity.

Wind speed variations due to roll circulations of more than $3 \mathrm{~m} \mathrm{~s}^{-1}$ at $100 \mathrm{~m}$ height were seen over the course of the day during up to 11 hours from model simulations and possibly even longer times. The horizontal wind speed variations were largest at around these heights, which is where modern wind turbines are erected. This increases the uncertainty of wind speed estimates, which can be of importance for short term wind power forecasts.

Advection of boundary layer rolls is likely to happen in high latitude coastal areas in spring and summer, when conditions are right. As an example, days with wind speeds larger than $10 \mathrm{~m} \mathrm{~s}^{-1}$ and Richardson gradient number less than -0.005 occur approximately 3 days per month in spring and summer in the study area over land. This value was calculated from climatological simulations with the WRF model over thirteen years. Since the Baltic Sea is surrounded by land areas with relatively short fetches, this means that most wind directions will influence the sea.

In summary, it has been shown that advection of land features across a coastline is possible and can affect the conditions offshore for long time periods and large offshore distances.

\section{Conflicts of Interest}

The authors declare that there are no conflicts of interest regarding the publication of this paper.

\section{Acknowledgments}

The study was performed as part of the STandUp for Wind research center. The simulations were performed on resources provided by the Swedish National Infrastructure for Computing (SNIC) at National Supercomputer Centre (NSC) at Linköping University. The Aqua/MODIS data was acquired from the Level-1 and Atmosphere Archive and Distribution System (LAADS) Distributed Active Archive Center (DAAC), located in the Goddard Space Flight Center in Greenbelt, Maryland (https://ladsweb.nascom.nasa.gov/). The work is part of the Licentiate thesis by Svensson [43].

\section{References}

[1] H. Kawase, T. Sato, and F. Kimura, "Numerical experiments on cloud streets in the lee of island arcs during cold-air outbreaks," Geophysical Research Letters, vol. 32, no. 14, 2005.

[2] M. Dörenkämper, M. Optis, A. Monahan, and G. Steinfeld, "On the Offshore Advection of Boundary-Layer Structures and the Influence on Offshore Wind Conditions," Boundary-Layer Meteorology, vol. 155, no. 3, pp. 459-482, 2015.

[3] B. W. Atkinson and J. W. Zhang, "Mesoscale shallow convection in the atmosphere," Reviews of Geophysics, vol. 34, no. 4, pp. 403-431, 1996.

[4] T. M. Weckwerth, J. W. Wilson, R. M. Wakimoto, and N. A. Crook, "Horizontal convective rolls: determining the environmental conditions supporting their existence and characteristics," Monthly Weather Review, vol. 125, no. 4, pp. 505-526, 1997.

[5] J. W. Glendening, "Lineal eddy features under strong shear conditions," Journal of the Atmospheric Sciences, vol. 53, no. 23, pp. 3430-3449, 1996.

[6] B. Brümmer, "Roll and cell convection in wintertime Arctic cold-air outbreaks," Journal of the Atmospheric Sciences, vol. 56, no. 15, pp. 2613-2636, 1999.

[7] J. A. Zhang, K. B. Katsaros, P. G. Black, S. Lehner, J. R. French, and W. M. Drennan, "Effects of roll vortices on turbulent fluxes in the hurricane boundary layer," Boundary-Layer Meteorology, vol. 128 , no. 2, pp. 173-189, 2008.

[8] Q. Huang, J. H. Marsham, D. J. Parker, W. Tian, and T. Weckwerth, "A comparison of roll and nonroll convection and the subsequent deepening moist convection: An LEM case study based on SCMS data," Monthly Weather Review, vol. 137, no. 1, pp. 350-365, 2009.

[9] G. S. Young, D. A. R. Kristovich, M. R. Hjelmfelt, and R. C. Foster, "Rolls, streets, waves, and more: a review of quasi-twodimensional structures in the atmospheric boundary layer," Bulletin of the American Meteorological Society, vol. 83, no. 7, pp. 997-1001, 2002.

[10] J. Hartmann, C. Kottmeier, and S. Raasch, "Roll vortices and boundary-layer development during a cold air outbreak," Boundary-Layer Meteorology, vol. 84, no. 1, pp. 45-65, 1997.

[11] S. Müller, E. V. Stanev, J. Schulz-Stellenfleth, J. Staneva, and W. Koch, "Atmospheric boundary layer rolls: Quantification of their effect on the hydrodynamics in the German Bight," Journal of Geophysical Research: Oceans, vol. 118, no. 10, pp. 5036-5053, 2013.

[12] T. M. Weckwerth, T. W. Horst, and J. W. Wilson, "An observational study of the evolution of horizontal convective rolls," Monthly Weather Review, vol. 127, no. 9, pp. 2160-2179, 1999. 
[13] A.-S. Smedman, "Occurrence of roll circulations in a shallow boundary layer," Boundary-Layer Meteorology, vol. 57, no. 4, pp. 343-358, 1991.

[14] W. Alpers and B. Brümmer, "Atmospheric boundary layer rolls observed by the synthetic aperture radar aboard the ERS-1 satellite," Journal of Geophysical Research: Oceans, vol. 99, no. C6, pp. 12613-12621, 1994.

[15] A. Chlond, "Three-dimensional simulation of cloud street development during a cold air outbreak," Boundary-Layer Meteorology, vol. 58, no. 1-2, pp. 161-200, 1992.

[16] M. Gryschka and S. Raasch, "Roll convection during a cold air outbreak: A large eddy simulation with stationary model domain," Geophysical Research Letters, vol. 32, no. 14, pp. 1-5, 2005.

[17] M. Gryschka, C. Drüe, D. Etling, and S. Raasch, "On the influence of sea-ice inhomogeneities onto roll convection in cold-air outbreaks," Geophysical Research Letters, vol. 35, no. 23, Article ID L23804, 2008.

[18] M. A. Lemone, F. Chen, M. Tewari et al., "Simulating the IHOP_2002 Fair-weather CBL with the WRF-ARW-Noah modeling system. Part II: Structures from a few kilometers to $100 \mathrm{~km}$ across," Monthly Weather Review, vol. 138, no. 3, pp. 745-764, 2010.

[19] W. Thurston, R. J. B. Fawcett, K. J. Tory, and J. D. Kepert, "Simulating boundary-layer rolls with a numerical weather prediction model," Quarterly Journal of the Royal Meteorological Society, vol. 142, no. 694, pp. 211-223, 2016.

[20] A. Smedman, H. Bergström, and B. Grisogono, "Evolution of stable internal boundary layers over a cold sea," Journal of Geophysical Research: Oceans, vol. 102, no. C1, pp. 1091-1099, 1997.

[21] N. Svensson, H. Bergström, E. Sahlée, and A. Rutgersson, "Stable atmospheric conditions over the Baltic Sea: Model evaluation and climatology," Boreal Environment Research, vol. 21, no. 5-6, pp. 387-404, 2016.

[22] D. Anderson, "Meteorological research flight Mk.2 HERCULES - Summary of capability," MRF Technical Note No. 21, 1997.

[23] B. A. Walter Jr. and J. E. Overland, "Observations of longitudinal rolls in a near neutral atmosphere.," Monthly Weather Review, vol. 112, no. 1, pp. 200-208, 1984.

[24] I. A. Renfrew and G. W. K. Moore, "An extreme cold-air outbreak over the Labrador Sea: Roll vortices and air-sea interaction," Monthly Weather Review, vol. 127, no. 10, pp. 23792394, 1999.

[25] H. Hersbach, "Comparison of C-Band scatterometer CMOD5.N equivalent neutral winds with ECMWF," Journal of Atmospheric and Oceanic Technology, vol. 27, no. 4, pp. 721-736, 2010.

[26] C. B. Hasager, M. Badger, A. Peña, X. G. Larsén, and F. Bingöl, "SAR-based wind resource statistics in the Baltic Sea," Remote Sensing, vol. 3, no. 1, pp. 117-144, 2011.

[27] M. Portabella and A. Stoffelen, "On Scatterometer Ocean Stress," Journal of Atmospheric and Oceanic Technology, vol. 26, no. 2, pp. 368-382, 2009.

[28] W. C. Skamarock and J. B. Klemp, "A time-split nonhydrostatic atmospheric model for weather research and forecasting applications," Journal of Computational Physics, vol. 227, no. 7, pp. 3465-3485, 2008.

[29] E.-M. Giannakopoulou and R. Nhili, "WRF model methodology for offshore wind energy applications," Advances in Meteorology, vol. 2014, Article ID 319819, 14 pages, 2014.
[30] D. P. Dee, S. M. Uppala, and A. J. Simmons, “The ERA-Interim reanalysis: configuration and performance of the data assimilation system," Quarterly Journal of the Royal Meteorological Society, vol. 137, no. 656, pp. 553-597, 2011.

[31] M. Nakanishi and H. Niino, "Development of an improved turbulence closure model for the atmospheric boundary layer," Journal of the Meteorological Society of Japan, vol. 87, no. 5, pp. 895-912, 2009.

[32] M. Tewari, F. Chen, W. Wang, and J. Dudhia, "Implementation and verification of the unified NOAH land surface model in the WRF model," in Proceedings of the 20th conference on weather analysis and forecasting/16th conference on numerical weather prediction, p. 1115, 2004, http://scholar.google.se/scholar.

[33] E. J. Mlawer, S. J. Taubman, P. D. Brown, M. J. Iacono, and S. A. Clough, "Radiative transfer for inhomogeneous atmospheres: RRTM, a validated correlated-k model for the longwave," Journal of Geophysical Research: Atmospheres, vol. 102, no. 14, pp. 16663-16682, 1997.

[34] J. Dudhia, "Numerical study of convection observed during the winter monsoon experiment using a mesoscale two-dimensional model," Journal of the Atmospheric Sciences, vol. 46, no. 20, pp. 3077-3107, 1989.

[35] G. A. Grell, "Prognostic evaluation of assumptions used by cumulus parameterizations," Monthly Weather Review, vol. 121, no. 3, pp. 764-787, 1993.

[36] G. Thompson, P. R. Field, R. M. Rasmussen, and W. D. Hall, "Explicit forecasts of winter precipitation using an improved bulk microphysics scheme. Part II. Implementation of a new snow parameterization," Monthly Weather Review, vol. 136, no. 12, pp. 5095-5115, 2008.

[37] J. Arnqvist, A. Segalini, E. Dellwik, and H. Bergström, "Wind Statistics from a Forested Landscape," Boundary-Layer Meteorology, vol. 156, no. 1, pp. 53-71, 2015.

[38] I. M. Brooks and D. P. Rogers, "Aircraft observations of boundary layer rolls off the coast of California," Journal of the Atmospheric Sciences, vol. 54, no. 14, pp. 1834-1849, 1997.

[39] D. Etling and R. A. Brown, "Roll vortices in the planetary boundary layer: a review," Boundary-Layer Meteorology, vol. 65, no. 3, pp. 215-248, 1993.

[40] D. Vickers, L. Mahrt, J. Sun, and T. Crawford, "Structure of offshore flow," Monthly Weather Review, vol. 129, no. 5, pp. 12511258, 2001.

[41] J. Ching, R. Rotunno, M. LeMone et al., "Convectively Induced Secondary Circulations in Fine-Grid Mesoscale Numerical Weather Prediction Models," Monthly Weather Review, vol. 142, no. 9, pp. 3284-3302, 2014.

[42] R. R. da Silva, A. W. Gandu, L. D. A. Sá, and M. A. F. S. Dias, "Cloud streets and land-water interactions in the Amazon," Biogeochemistry, vol. 105, no. 1, pp. 201-211, 2011.

[43] N. Svensson, Wind and atmospheric stability characteristics over the Baltic Sea [Licentiate thesis], Uppsala University, 2016. 

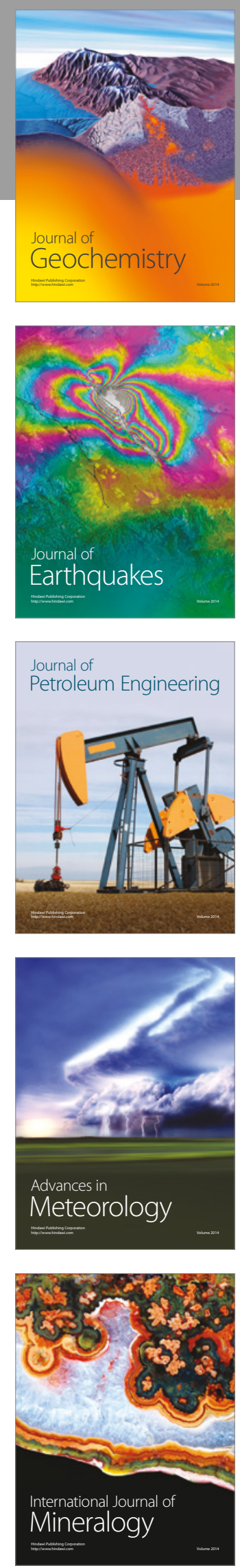
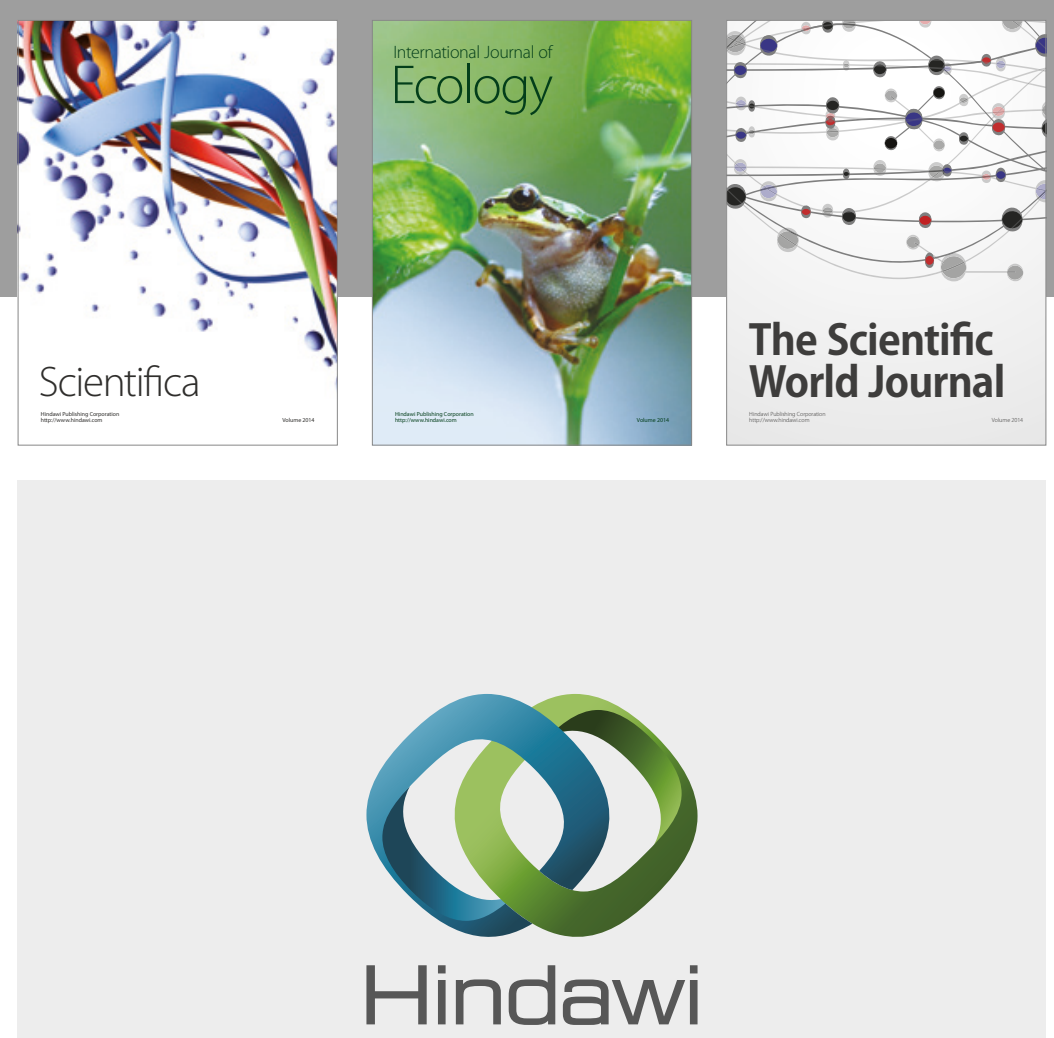

Submit your manuscripts at

https://www.hindawi.com
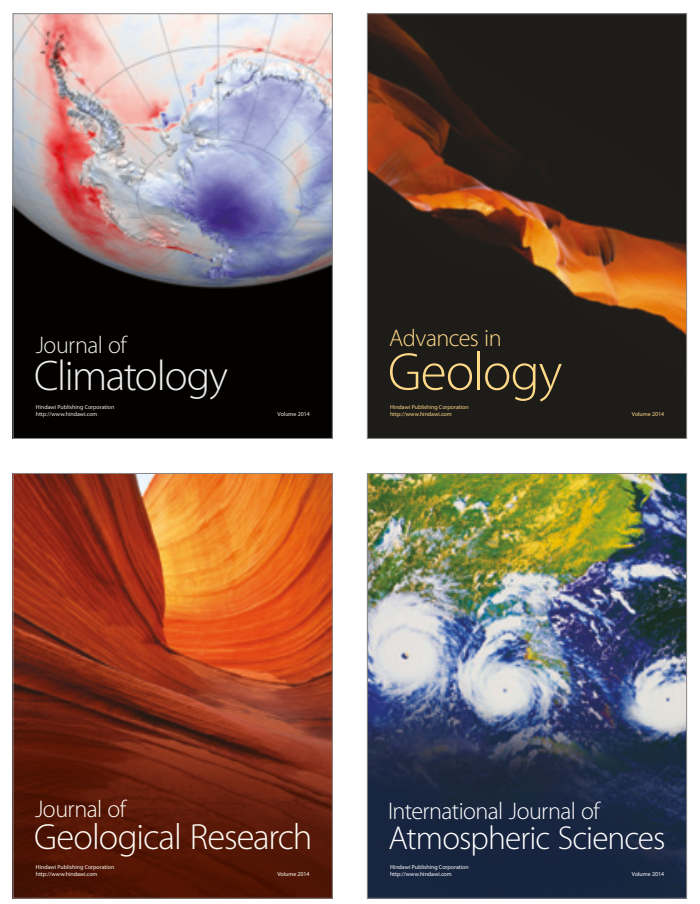

The Scientific

World Journal
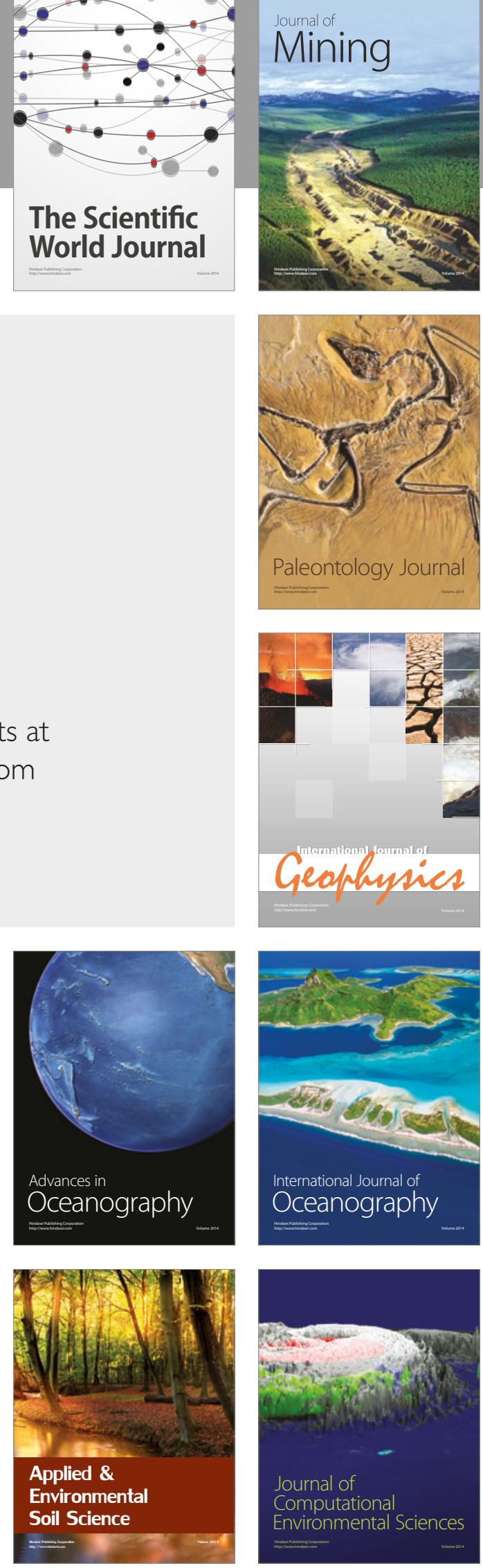